\title{
Nanoparticles for Stem Cell Therapy Bioengineering in Glioma
}

\author{
Henry Ruiz-Garcia ${ }^{1,2}$, Keila Alvarado-Estrada², Sunil Krishnan', \\ Alfredo Quinones-Hinojosa ${ }^{2}$ and Daniel M. Trifiletti ${ }^{1,2 *}$ \\ ${ }^{1}$ Department of Radiation Oncology, Mayo Clinic, Jacksonville, FL, United States, ${ }^{2}$ Department of Neurological Surgery, \\ Mayo Clinic, Jacksonville, FL, United States
}

OPEN ACCESS

Edited by:

João Conde,

New University of Lisbon, Portugal

Reviewed by:

Jorge Matias-Guiu,

Complutense University of Madrid,

Spain

Ulises Gomez-Pinedo,

Instituto de Investigación Sanitaria del

Hospital Clínico San Carlos, Spain

Heather Sheardown,

McMaster University, Canada

*Correspondence:

Daniel M. Trifilett

trifiletti.daniel@mayo.edu

Specialty section:

This article was submitted to

Biomaterials,

a section of the journal

Frontiers in Bioengineering and

Biotechnology

Received: 02 May 2020

Accepted: 19 October 2020

Published: 07 December 2020

Citation:

Ruiz-Garcia H,

Alvarado-Estrada K, Krishnan S,

Quinones-Hinojosa A and Trifiletti DM (2020) Nanoparticles for Stem Cell

Therapy Bioengineering in Glioma.

Front. Bioeng. Biotechnol. 8:558375.

doi: 10.3389/fbioe.2020.558375
Gliomas are a dismal disease associated with poor survival and high morbidity. Current standard treatments have reached a therapeutic plateau even after combining maximal safe resection, radiation, and chemotherapy. In this setting, stem cells (SCs) have risen as a promising therapeutic armamentarium, given their intrinsic tumor homing as well as their natural or bioengineered antitumor properties. The interplay between stem cells and other therapeutic approaches such as nanoparticles holds the potential to synergize the advantages from the combined therapeutic strategies. Nanoparticles represent a broad spectrum of synthetic and natural biomaterials that have been proven effective in expanding diagnostic and therapeutic efforts, either used alone or in combination with immune, genetic, or cellular therapies. Stem cells have been bioengineered using these biomaterials to enhance their natural properties as well as to act as their vehicle when anticancer nanoparticles need to be delivered into the tumor microenvironment in a very precise manner. Here, we describe the recent developments of this new paradigm in the treatment of malignant gliomas.

Keywords: biomaterials, nanotechnology, nanoparticles, stem cells, glioma, bioengineering, targeting, surface functionalization

\section{INTRODUCTION}

Gliomas are a dismal entity, associated with poor survival and high morbidity. The current standard of care has reached a therapeutic plateau even after combining maximal safe resection and chemoradiation (Stupp et al., 2005; Cantrell et al., 2019). In this setting, stem cell therapies have risen as a promising therapeutic approach for gliomas; however, there still exist crucial drawbacks holding its pass to an extensive acceptance in clinical applications. The development of nanomedicine is a parallel phenomenon with potential deep implications in the way stem cells will be introduced into human glioma therapy. Stem cells can be engineered using this nanotechnology in different ways in order to increase our understanding about their biology, improve stem cells antitumor properties, and synergize them with other approaches such as chemotherapy, radiation, thermotherapy, etc. (Kim et al., 2011; Mangraviti et al., 2016; Karlsson et al., 2019; Kozielski et al., 2019; Tian et al., 2020). We aim to provide an overview of the foundations of stem cell therapy and nanoparticles to then explore the potential synergy between these two, through an up-to-date analysis of the benefits of coupling both therapeutic approaches.

\section{GLIOMAS}

Gliomas are the most common and devastating primary brain tumors, representing approximately $75 \%$ of these. According to the World Health Organization (WHO), gliomas are classified in 
four histological grades (I-IV), being the glioblastomas the corresponding WHO grade IV tumor. Glioblastoma (GBM) is the most common and aggressive among all gliomas, accounting for $57.3 \%$ of the tumors in this group, with around 12,500 new cases diagnosed every year only in United States (Cantrell et al., 2019; Ostrom et al., 2019). Glioblastomas present a median overall survival of 15 months and a 5-year survival rate of only $4.6 \%$ even after maximal therapy (Cantrell et al., 2019). Furthermore, most of the patients diagnosed with gliomas of lower grade, such as astrocytomas and oligodentrogliomas grade II and III (anaplastic), will eventually progress and perish because of the disease. Overall, these facts are just the translation of the need to develop novel therapeutic approaches able to help extend survival and improve the quality of life of patients with the diagnosis of glioma.

\section{Limitation of Current Therapies}

The current gold standard for the treatment of gliomas includes surgery and chemoradiation. Maximal safe resection is advised in all cases regardless of the WHO grade, given that the overall survival is positively correlated with the extent of resection (EOR) (McGirt et al., 2008, 2009; Chaichana et al., 2014a,b,c; Mahato et al., 2018; Mampre et al., 2018; Marenco-Hillembrand et al., 2020; Suarez-Meade et al., 2020). However, surgery is not curative in any case. Chemotherapy and radiation are required for highgrade gliomas. Anaplastic astrocytomas and oligodendrogliomas (grade III gliomas) will require chemoradiation depending on clinical parameters and tumor molecular characteristics (Caccese et al., 2020). Glioblastoma tumors require postoperative radiotherapy, with concurrent and adjuvant chemotherapy. Unfortunately, despite this multidisciplinary treatment, gliomas will inevitably recur due to their infiltrative nature and high treatment resistance (Cantrell et al., 2019). By the time of surgery, it is estimated that glioma cells have already migrated beyond the macroscopically identifiable tumor, and thereafter, these cells will ultimately seed local recurrence around the surgical cavity (75-80\% of cases) and/or non-local recurrence in the reminder 20-25\% of cases (Brandes et al., 2009; Chamberlain, 2011; Drumm et al., 2019).

A subset of gliomas cells have been pinpointed as the culprit of this recurrence. The glioma cancer stem cells (CSCs) are a subgroup of malignant cells with the potential of self-renewal, forming tumors that resemble the original pathology, as well as high resistance to current chemotherapeutics and radiation (Singh et al., 2003; Galli et al., 2004; Beier et al., 2007; Li et al., 2009; Cheng L. et al., 2013; Dahan et al., 2014). These cells migrate beyond the macroscopic tumor, infiltrating apparent normal brain parenchyma by the time of surgery and survive even after receiving high-dose radiation and chemotherapy ( $\mathrm{Li}$ et al., 2009; Lathia et al., 2012). As these cells migrate beyond the tumor bulk to seed further recurrence, a therapeutic strategy able to track these newly developed microscopic glioma foci to deliver antitumor cargoes is of utmost importance. In this setting, the use of neural and mesenchymal stem cells (MSCs) as a therapeutic armamentarium against gliomas represents a potential avenue to achieve this goal and alter the treatment paradigm of this dismal cancer (Pendleton et al., 2013; Li et al., 2014; Smith et al., 2015; Mangraviti et al., 2016).

\section{STEM CELLS AS ELEMENTS OF THERAPY FOR MALIGNANT GLIOMA}

Stem cells have risen as a promising therapeutic option for the treatment of malignant gliomas, as they would be able to migrate and home into glioma tumors, including microscopic tumor foci, which harbor the potential to seed future recurrence (Brown et al., 2003; Nakamura et al., 2004; Kim et al., 2005, 2018; Sonabend et al., 2008; Thu et al., 2009; Yong et al., 2009; van Eekelen et al., 2010; Amano et al., 2011; Choi et al., 2011; Kleinschmidt et al., 2011; Ryu et al., 2011; Altanerova et al., 2012; Jiao et al., 2012; Kosaka et al., 2012; Cheng Y. et al., 2013; Huang et al., 2013, 2014; Lee et al., 2013; Balyasnikova et al., 2014; Li et al., 2014; Mooney et al., 2014b; Bryukhovetskiy et al., 2015; de Melo et al., 2015; Martinez-Quintanilla et al., 2015; Morshed et al., 2015; Park et al., 2015; Cheng S. H. et al., 2016; Kim S. J. et al., 2016; Kim S. M. et al., 2016; Liu et al., 2016; Mangraviti et al., 2016; Muroski et al., 2016; Meca-Cortes et al., 2017; Portnow et al., 2017; Hsu et al., 2018; Lang et al., 2018; Pavon et al., 2018; Tirughana et al., 2018; Zhang et al., 2018; Huang R. Y. et al., 2019; Tanrikulu et al., 2019; Allahverdi et al., 2020; Jabbarpour et al., 2020). Stem cells are relatively easy to grow in vitro and can be bioengineered to deliver a wide range of antitumor payloads such as proteins, oncolytic viruses, prodrugs, small interfering RNA (siRNA), and nanoparticles (Brown et al., 2003; Nakamura et al., 2004; Kim et al., 2005, 2018; Sonabend et al., 2008; Thu et al., 2009; Yong et al., 2009; van Eekelen et al., 2010; Amano et al., 2011; Choi et al., 2011; Kleinschmidt et al., 2011; Ryu et al., 2011; Altanerova et al., 2012; Jiao et al., 2012; Kosaka et al., 2012; Cheng Y. et al., 2013; Huang et al., 2013, 2014; Lee et al., 2013; Balyasnikova et al., 2014; Li et al., 2014; Mooney et al., 2014b; Bryukhovetskiy et al., 2015; de Melo et al., 2015; MartinezQuintanilla et al., 2015; Morshed et al., 2015; Park et al., 2015; Cheng S. H. et al., 2016; Kim S. J. et al., 2016; Kim S. M. et al., 2016; Liu et al., 2016; Mangraviti et al., 2016; Muroski et al., 2016; MecaCortes et al., 2017; Portnow et al., 2017; Hsu et al., 2018; Lang et al., 2018; Pavon et al., 2018; Tirughana et al., 2018; Zhang et al., 2018; Huang R. Y. et al., 2019; Tanrikulu et al., 2019; Allahverdi et al., 2020; Jabbarpour et al., 2020).

Stem cells are undifferentiated cells with capacity of selfrenewal and differentiation by definition. They can mature along symmetric and asymmetric replication processes. The later type of cell division will result in different hierarchies within stem cell niches, which will now include progenitor cells; these are daughter cells retaining the same stem cells properties but with a de novo limited differentiation ability (Young et al., 2014).

\section{Stem Cell Classification}

Stem cells can be designated according to their developmental status as adult, fetal, or embryonic stem cells. Their differentiation potential can further define them as totipotent, pluripotent, or multipotent stem cells. Totipotent stem cells are only found during the very first days of life just after fecundation and have the 
capacity to derive into any type of human cells, including placental tissues. Once the embryo has reached the blastocyst stage, cells contained inside the inner cell mass are defined as pluripotent, as they can differentiate into any cell of all three germ layers but no placental tissues (Takahashi and Yamanaka, 2006; Qiao et al., 2018; Andres et al., 2019; Klimanskaya, 2019). Eventually, these pluripotent stem cells will restrict their differentiation potential to only one of the three germ cell layers and thereafter will be defined as multipotent stem cells, which can actually be harvested from most of the organs of the human body (Takahashi and Yamanaka, 2006; Qiao et al., 2018; Andres et al., 2019; Klimanskaya, 2019).

Stem cells used in glioma therapy are usually multipotent cells obtained from adult or fetal organs. In particular, neural stem cells (NSCs), mesenchymal stem cells (MSCs), and hematopoietic stem cells (HSCs) are the most common multipotent stem cells used with this purpose (Aboody et al., 2000; Portnow et al., 2017). It is noteworthy, however, that pluripotent cells such as the induced-pluripotent stem cells (iPSC) or embryonic pluripotent stem cells have also been described in cell therapy against glioma (Parker Kerrigan et al., 2018; Table 1).

\section{Development of Stem-Cell-Based Glioma Therapy}

The use of stem cells in glioma therapy relies on their tumorhoming properties. This property was first described in 2000 by Aboody et al. The group presented a seminal paper describing the glioma tropism of neural stem cells. The study reported on the capacity of NSC for engrafting into the glioma bulk when intratumor NSC injections were performed, invading normal parenchyma only when tumor cells migrate far from the tumor mass; with this, they also showed the specific NSC ability to track glioma cancer cells infiltrating along healthy tissue. NSCs were also proven to migrate toward glioma tumor masses when implanted distally to these, through ipsilateral,

TABLE 1 | Classification and major features of stem cells reported in glioma therapy.

\begin{tabular}{|c|c|c|c|}
\hline Stem cell & Defining criteria & Source/Niche & Linage \\
\hline \multicolumn{4}{|c|}{ Pluripotent stem cells: capacity to differentiate into any cell of all three germ layers } \\
\hline Embryonic stem cells (ECSs) & $\begin{array}{l}\text { Markers of pluripotency as found in } \\
\text { ICM cells: } \\
\text { Transcription factors: Oct4, Nanog, } \\
\text { Rex-1 } \\
\text { Cell surface markers: SSEA-3, } \\
\text { SSE-A4, TRA-1-60, TRA-1-81, alkaline } \\
\text { phosphatase }\end{array}$ & $\begin{array}{l}\text { Blastocyst } \\
\text { Morula } \\
\text { Growth-arrested embryos } \\
\text { Somatic cell nuclear transfer } \\
\text { Single blastomere }\end{array}$ & As defined by pluripotency \\
\hline Induce pluripotent stem cells (iPSCs) & Essentially the same than ECS markers & $\begin{array}{l}\text { Reprogrammed adult somatic } \\
\text { cells-usually fibroblasts or skin cells. }\end{array}$ & $\begin{array}{l}\text { As defined by pluripotency } \\
\text { given than iPSC are functionally } \\
\text { equivalent to ECS }\end{array}$ \\
\hline
\end{tabular}

Multipotent stem cells: capacity to differentiate into cells of one of the three germ layers

Neural stem cells (NSCs)

Mesenchymal stem cells (MSCs)

Hematopoietic stem cells (HMSs)
Positive: GFAP, CD133, CD184, and Nestin, Sox1, Sox2, and Pax6

Negative: CD271, CD44, CD24

Immune profile: Absent HLA II

MSC must comply with ISCT criteria: Positive (>95\% +): CD105, CD73, CD90

Negative (<2\% -): CD45, CD34, CD14 or CD11b, CD79a, or CD19, HLA DR

Adherence to plastic in standard culture conditions In vitro differentiation to osteoblast, adipocytes, and chondroblasts.

Immune profile: Absent HLA II

Negative: CD45R/B220 (B cells), Gr-1 (granulocytes), Mac-1 (macrophages), Ter-119 (erythrocytes) and CD4/CD8 (lymphocytes)-for phenotypic enrichment.

Positive: Sca-1, c-Kit, CD150

*They appear as side population in dye exclusion assays due to the high expression of MDR pumps
Subependymal zone (SEZ) - lining the lateral ventricles

Dentate gyrus of the hippocampus

*Obtained from fetal and adult mammals

Adult tissues: adipose tissue, bone marrow, peripheral blood, dental pulp, ligamentum flavum, synovium, endometrium, sweat glands, and milk Fetal tissues: umbilical cord, umbilical cord blood, Wharton jelly, amniotic fluid, chorionic villi, and placenta

Adult tissues: bone marrow, peripheral blood Non-adult tissues: umbilical cord blood, yolk sac, liver, spleen
Neurons

Oligodendrocytes

Astrocytes

Ependymal cells

Osteoblast

Adipocytes

Chondroblast

*Differentiation into ectodermal and endodermal linages has also been reported

IMC, inner mass cells; MDR, multidrug resistance. 
contralateral, and intraventricular NSC injections (Aboody et al., 2000). These abilities and the possibility of being bioengineered to secrete antiglioma cargoes turned NSC into a promising glioma treatment, able to track and tackle this infiltrative malignant tumor. Importantly, NSC showed to retain their stem cell properties and had been proven non-tumorigenic (Snyder et al., 1992). In 2017, the same group published the first phase I clinical trial where NSC-based antiglioma therapy was proven safe; the proof of concept of NSC tumor homing was also demonstrated by the group (Portnow et al., 2017). Unfortunately, despite the encouraging role of NSC in glioma therapy, limited availability of human NSC (hNSC) as well as ethical concerns regarding its use encouraged researchers to seek alternatives sources of stem cells.

Mesenchymal stem cells (MSCs) were first described by Friedenstein more than 50 years ago (Friedenstein et al., 1968, 1970, 1974). He initially isolated MSC from rodent bone marrow and proved that they were able to differentiate into mesenchymal tissue (adipogenic, chondrogenic, and osteogenic differentiation). MSCs ended up being an alternative to the difficult-to-obtain NSC, as they are abundant in several adult and fetal tissues such as bone marrow (BM-MSC) (Friedenstein et al., 1968, 1970, 1974), adipose tissue (A-MSC) (Zuk et al., 2001; Katz et al., 2005; Wagner et al., 2005), umbilical cord (UCMSC) (Girdlestone et al., 2009), umbilical cord blood, Wharton jelly (Erices et al., 2000; Zeddou et al., 2010), endometrium (Meng et al., 2007), dental pulp (Agha-Hosseini et al., 2010), ligamentum flavum (Chen et al., 2011), etc. (Kassis et al., 2006; Miao et al., 2006; Roubelakis et al., 2007; Poloni et al., 2008; Patki et al., 2010; Ma et al., 2018). MSCs are easy to harvest and isolate even from adult individuals, which would allow for using patient-derived MSC as autografts in glioma patients, thus avoiding ethical dilemmas as well as fears about immunemediated allograft rejection. In this context where MSCs could be isolated from a variety of tissue sources, cultured following different methodologies, and be defined by using different surface markers, the Mesenchymal and Tissue Stem Cell Committee of the International Society for Cellular Therapy (ISCT) proposed a standard set of minimum criteria defining MSC for both laboratory-based scientific investigations and preclinical studies (Dominici et al., 2006). Thus, every study currently under development should follow these guidelines in order to assure a better cell homogeneity among different laboratories and greater reproducibility.

The first report on the use of MSC in the treatment of gliomas came from Nakamura et al. In 2004, the group demonstrated that MSCs also possessed glioma-homing properties by proving rat-derived BM-MSC homing in a rat glioma model. In 2005, Nakamizo et al. were able to replicate the findings using human BM-MSC on a murine model harboring glioma xenograft derived from commercial human cell lines (U87, U251, and LN229). Furthermore, both groups were able to bioengineer the MSCs to deliver antitumor cargoes. To date, several reports on the use of MSC as key elements for glioma stem cell therapy have been published with exceptional promising results (Table 2; Brown et al., 2003; Nakamura et al., 2004; Kim et al., 2005, 2018; Sonabend et al., 2008; Thu et al., 2009; Yong et al., 2009; van Eekelen et al., 2010; Amano et al., 2011; Choi et al., 2011; Kleinschmidt et al., 2011; Ryu et al., 2011; Altanerova et al.,
2012; Jiao et al., 2012; Kosaka et al., 2012; Cheng Y. et al., 2013; Huang et al., 2013, 2014; Lee et al., 2013; Balyasnikova et al., 2014; Li et al., 2014; Mooney et al., 2014b; Bryukhovetskiy et al., 2015; de Melo et al., 2015; Martinez-Quintanilla et al., 2015; Morshed et al., 2015; Park et al., 2015; Cheng S. H. et al., 2016; Kim S. J. et al., 2016; Kim S. M. et al., 2016; Liu et al., 2016; Mangraviti et al., 2016; Muroski et al., 2016; Meca-Cortes et al., 2017; Portnow et al., 2017; Hsu et al., 2018; Lang et al., 2018; Pavon et al., 2018; Tirughana et al., 2018; Zhang et al., 2018; Huang R. Y. et al., 2019; Tanrikulu et al., 2019; Allahverdi et al., 2020; Jabbarpour et al., 2020).

On the other hand, not all are in agreement, as there has been a risen controversy in which some authors have described that MSCs could eventually support glioma tumor growth. Different types of MSCs such as BM-MSC, A-MSC, and UC-MSC have been associated with these proglioma effects through increased proliferation, cancer cells migration, angiogenesis, transition to epithelial-mesenchymal phenotype, and decreased glioma apoptosis (Iser et al., 2016; Ridge et al., 2017); however, this adverse phenotype would vary on a differential basis depending on specific glioma tumors (Breznik et al., 2017). In this same line, brain tumor-derived MSC (BT-MSC) have also been described in mouse- and human-derived glioma tumors supporting glioma microenvironment (Behnan et al., 2014; Guo et al., 2014; Svensson et al., 2017; Yi et al., 2018). In support to these findings, Shahar et al. showed that higher percentages of human BT-MSC directly correlate with worse patient prognosis (Shahar et al., 2017). Overall, these data would suggest that stem cell therapy should be carefully selected in future translational efforts.

In order to improve different aspects of stem cell therapies against glioma, different approaches have been studied. The use of nanoparticles for stem cell bioengineering is one of these potential approaches and will be discussed in the following section.

\section{NANOPARTICLES AS ELEMENTS OF THERAPY FOR MALIGNANT GLIOMA}

Nanoparticles (NPs) are defined as nanomaterials sized between 1 and $100 \mathrm{~nm}$ in at least one of their external dimensions, which confer them a high surface/volume ratio (European Commission, 2011). Due to this small size, they present significantly different properties when compared to conventional materials of non-nanometric scale. The optical, magnetic, electronic, and biological properties of these nanomaterials can be tuned by size, shape, surface modifications (functionalization), or even by combining them with different materials in order to create new heterostructured nanoparticles (Thimsen et al., 2014; Lee et al., 2017).

In Nano-oncology, nanoparticles represent an important diagnostic and therapeutic tool, as they can be designed to interact with most biological system with great precision and specificity. This is possible due to their particular physicochemical characteristics and the possibility of making them able to target a specific tissue, specific cell types, or a specific cellular compartment (targeted functionalization) (Portney and Ozkan, 2006). The potential benefits of these nanomaterials in 
TABLE 2 | Stem cell therapy in glioma.

\begin{tabular}{|c|c|c|}
\hline Stem cell type & Delivery routes & Applications \\
\hline \multirow[t]{7}{*}{ Neural stem cells ${ }^{a, b}$} & \multirow{7}{*}{$\begin{array}{l}\text { - Intravascular: vein (Brown et al., 2003) } \\
\text { - Intracranial (Mooney et al., 2014b; Morshed } \\
\text { et al., 2015) } \\
\text { - Intraventricular } \\
\text { - Intracerebral (Altanerova et al., 2012; de Melo } \\
\text { et al., 2015) }\end{array}$} & $\begin{array}{l}\text { Prodrug activating enzymes: CD (Portnow et al., 2017), rCE, and hCE1m6 (Mooney } \\
\text { et al., 2014b), HSV-TK (Uhl et al., 2005; Tamura et al., 2020) }\end{array}$ \\
\hline & & Oncolytic viruses: CRAd-S-pk7 (Morshed et al., 2015) \\
\hline & & Cargo proteins: IL-4 (Benedetti et al., 2000), IL-12 (Ehtesham et al., 2002), PF-4 (Lee \\
\hline & & $\begin{array}{l}\text { et al., 2003), TRAlL (Balyasnikova et al., 2011), PEX (Kim et al., 2005), BMP4 (Liu et al., } \\
\text { 2016), TSP-1 (van Eekelen et al., 2010) }\end{array}$ \\
\hline & & Nanoparticles (Mooney et al., 2014b) \\
\hline & & $\begin{array}{l}\text { - Stem cells tracking: FE-Pro (Thu et al., 2009), FTD (Kim S. J. et al., 2016) via MRI, } \\
\text { MSN (Cheng S. H. et al., 2016) via SPECT/CT }\end{array}$ \\
\hline & & • Payload release: SD (Muroski et al., 2016)**, MSN-Dox (Cheng Y. et al., 2013) \\
\hline
\end{tabular}

\section{Mesenchymal stem cells \\ Adipose-derived \\ - Intranasal (Balyasnikova et al., 2014) - Intracranial (Altanerova et al., 2012; de Melo et al., 2015)}

Bone marrow-derived

\begin{abstract}
Human placenta-derived
\end{abstract}
- Intratumoral (Lee et al., 2013)

Umbilical cord-derived

Amniotic

membrane-derived

Hematopoietic progenitor cells

- Intratumoral (Kosaka et al., 2012; Lee et al., 2013): alginate microencapsulated (Kleinschmidt et al., 2011)

- Intracarotid (Yong et al., 2009)

CD, cytosine deaminase; rCE, rabbit carboxylesterase; hCE1m6, modified human carboxylesterase; MSN-Dox, doxorubicin loaded-mesoporous silica nanoparticles; FE-Pro, ferumoxide-protamine sulfate complex; FTD, FerraTrack Direct; NIR675, NEO-LIVE, Magnoxide 675 nanoparticles; MSN, mesoporous silica nanoparticles; MTN, magnetic ternary nanohybrid; IO MNP, iron-based magnetic nanoparticles; MNP, mesoporous nanoparticles; NK4, hepatocyte growth factor antagonist; PEG-SPIO, polyethylene glycol-superparamagnetic iron oxide; PF-4, platelet factor 4.

*MSC were found to promote tumor growth.

**2u magnetic disks.

***Only specified as human MSC.

${ }^{a}$ GMP production and scale-up of these cells have been performed (Tirughana et al., 2018).

${ }^{b}$ First-in human studies have been performed assessing safety of intracranial injection (Portnow et al., 2017).

${ }^{c}$ Modified MSC produced by CRISPR/Cas9.

medicine have led some of them to obtain Food and Drug Administration (FDA) approval to be investigated under several clinical protocols (Table 3).

\section{Targeted Functionalization}

In order to achieve a targeted distribution at a cellular or even intracellular level, NPs can be functionalized via active targeting. Active targeting is achieved by different methods; a method called ligand targeting works by coating the nanoparticles' surface with one or more ligands such as transferrin, epidermal
Prodrug activating enzymes: yeast CD (Altanerova et al., 2012), HSV-TK

(Meca-Cortes et al., 2017) $^{(\mathrm{C})}$, (de Melo et al., 2015)

Oncolytic viruses: ICOVIR17 (Martinez-Quintanilla et al., 2015)

Cargo proteins: TRAIL (Balyasnikova et al., 2014; Tanrikulu et al., 2019)

Oligonucleotides: miR-4731 (Allahverdi et al., 2020)

Prodrug activating enzymes: CD (Kosaka et al., 2012), HSV-TK (Amano et al., 2011) Oncolytic viruses: Delta24-RGD (Yong et al., 2009), CRAd (Sonabend et al., 2008) ${ }^{\star \star \star}$ Cargo Proteins: IL2 (Nakamura et al., 2004), INF-B (Park et al., 2015), TRAIL (Choi et al., 2011), BMP4 (Li et al., 2014; Mangraviti et al., 2016)

Oligonucleotides: miR-124 (Lang et al., 2018; Lee et al., 2013) and miR-145 (Lee et al., 2013), miRNA-584-5p (Kim et al., 2018)

Nanoparticles:

- Gene therapy: MTN (TRAIL) (Huang R. Y. et al., 2019)

-Intrinsic MSC modification: IO MNP (improve MSC homing) (Huang et al., 2014)

•Stem cell tracking: MNP (Huang et al., 2013), FTD (Kim S. J. et al., 2016) via MRI.

NIR675 (Kim S. M. et al., 2016) via near-infrared imaging

Cargo proteins: NK4 (Jabbarpour et al., 2020)

Oligonucleotides: miR-124 and miR-145 (Lee et al., 2013)

Nanoparticles

- Stem cell tracking: PEG-SPIO (Hsu et al., 2018) via MRI

Cargo proteins: IL12 (Ryu et al., 2011)

Oligonucleotides: miR-124 and miR-145 (Lee et al., 2013)

Nanoparticles

- Stem cell tracking: MION-Rh (Pavon et al., 2018)*

Direct antiglioma properties: increased apoptosis (Jiao et al., 2012)

Migration in an in vitro model (Bryukhovetskiy et al., 2015) growth factor (EGF), folic acid, arginyl-glycyl-aspartic tripeptide (RGD) peptide, hyaluronic acid, antibodies, and others (RuizGarcia et al., 2020). These ligands allow NPs to bind specific "receptors" differentially expressed only in certain cancerous blood vessels and/or tumor cells, thus leading to a precise cellular internalization (Maier-Hauff et al., 2007; Kim et al., 2010; Wegscheid et al., 2014; Cheng Y. et al., 2016; Shen et al., 2017; Yu et al., 2017, 2019; Hua et al., 2018; Daniel et al., 2019; Denora et al., 2019; Dufort et al., 2019; Kefayat et al., 2019; Kunoh et al., 2019; Luque-Michel et al., 2019; Rego et al., 2019, 2020; Ruan et al., 
TABLE 3 | Advances in the uses of nanoparticles in glioma therapy and diagnosis.

\begin{tabular}{|c|c|}
\hline Use & Experimental setting and nanoparticle type \\
\hline $\begin{array}{l}\text { Nanocarrier: Drug bioavailability/therapeutic efficacy enhancer } \\
\text { - Usually loaded with drugs such as doxorubicin or biological agents such as } \\
\text { siRNA (Yu et al., 2017) } \\
\text { - Usually functionalized with ligands of common GBM membrane proteins }\end{array}$ & $\begin{array}{l}\text { Preclinical: } \\
\text { - In vivo: PLGA-NP (Sousa et al., 2019; Ye et al., 2019; Caban-Toktas et al., 2020; } \\
\text { Chung et al., 2020), RGD-NP (Ullah et al., 2020), oleic acid NP } \\
\text { (Wang H. et al., 2020) } \\
\text { - In vitro only: PLGA-NP (Luque-Michel et al., 2019; Ferreira et al., 2020; } \\
\text { Roberts et al., 2020), ethyl arachidate (TPLN) (Alves et al., 2020), FONP } \\
\text { (Daniel et al., 2019), pSiNPs }\end{array}$ \\
\hline Standalone therapy & $\begin{array}{l}\text { Preclinical } \\
\text { • In vitro: Selenium NP (Xu et al., 2020), MNP (Shen et al., 2017) } \\
\text { • In vivo: MP (Cheng Y. et al., 2016; Kim et al., 2010) }\end{array}$ \\
\hline Drug sensitizer & $\begin{array}{l}\text { Temozolomide: direct attenuation on EGFR and MET signaling, through delivered } \\
\text { miRNAs (Meng et al., 2020) }\end{array}$ \\
\hline Imaging technologies enhancer & Fluorescence: USPION (Denora et al., 2019) \\
\hline Magnetic hyperthermia & $\begin{array}{l}\text { Clinical } \\
\text { • Phase I and II: SPION (Maier-Hauff et al., 2007; Wegscheid et al., 2014) } \\
\text { Preclinical } \\
\text { • In vivo: SPIONa (Rego et al., 2019, 2020; Shi et al., 2019) }\end{array}$ \\
\hline Sonodynamic therapy & $\begin{array}{l}\text { Preclinical } \\
\text { - In vivo: (Liang et al., 2020) }\end{array}$ \\
\hline Radiotherapy enhancer & $\begin{array}{l}\text { Charged particles } \\
\text { - Proton (Martinez-Rovira et al., 2020) } \\
\text { - Helium } \\
\text { - Carbon } \\
\text { - Oxygen } \\
\text { Photon therapy (X-rays) } \\
\text { - In vitro only: AuNP (Kunoh et al., 2019) } \\
\text { - In vivo: FA-AuNC (Kefayat et al., 2019), PEGylated-AgNP (Zhao et al., 2019), } \\
\text { PEGylated-liposome (Hua et al., 2018), AGulX (Dufort et al., 2019)* }\end{array}$ \\
\hline Photodynamic therapy enhancer & $\begin{array}{l}\text { Preclinical } \\
\text { - In vivo: 5-ALA (Wang X. et al., 2020), AuNS (Zhu et al., 2020)a , ICG } \\
\text { (ZhuGe et al., 2019) }\end{array}$ \\
\hline Immunotherapy enhancer & Functionalization with anti-PDL1 (Ruan et al., 2019; Zhang et al., 2019) \\
\hline
\end{tabular}

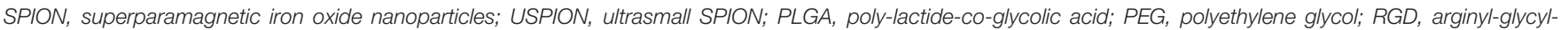

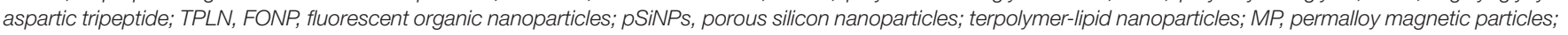
FA-AuNC, folic acid gold nanoclusters; AuNP, gold nanoparticles, AgNP, silver nanoparticles; AGulX, gadolinium-based nanoparticle; 5-ALA, 5-aminolevulinic acid; AuNS,

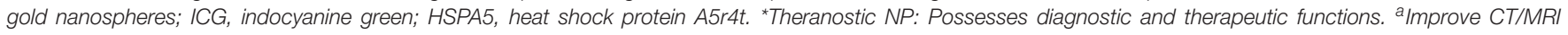
imaging and also works as radiosensitizer by AuNS properties and loading an HSPA inhibitor.

2019; Shi et al., 2019; Sousa et al., 2019; Ye et al., 2019; Zhang et al., 2019; Zhao et al., 2019; ZhuGe et al., 2019; Alves et al., 2020; Caban-Toktas et al., 2020; Chung et al., 2020; Ferreira et al., 2020; Kazmi et al., 2020; Liang et al., 2020; Martinez-Rovira et al., 2020; Meng et al., 2020; Roberts et al., 2020; Ullah et al., 2020; Wang H. et al., 2020; Wang X. et al., 2020; Xu et al., 2020; Zhu et al., 2020; see Table 3 for examples of ligand targeting in glioma research).

Another active targeting method to increase functional specificity of NPs that are used as gene delivery systems is the transcriptional targeting, which can occur at a transcriptional or posttranscriptional level (Golombek et al., 2018). Here, the delivered gene includes a tumor-specific promoter (highly functional only in cancer cells), which will secure a well-localized expression of the transgene, limited to occur only inside the cancer cells of interest. Posttranscriptional regulations of the product encoded by the exogenously delivered gene are achieved by controlling RNA splicing, RNA stability, and initiation of the RNA translation once it is present in the cancer cell (Maier-Hauff et al., 2007; Kim et al., 2010; Wegscheid et al., 2014; Cheng Y. et al., 2016; Shen et al., 2017; Yu et al., 2017; Hua et al., 2018; Daniel et al., 2019; Denora et al., 2019; Dufort et al., 2019; Kunoh et al., 2019; Luque-Michel et al., 2019; Ruan et al., 2019; Rego et al., 2019, 2020; Shi et al., 2019; Sousa et al., 2019; Ye et al., 2019; Zhang et al., 2019; Zhao et al., 2019; ZhuGe et al., 2019; Alves et al., 2020; Caban-Toktas et al., 2020; Chung et al., 2020; Ferreira et al., 2020; Kazmi et al., 2020; Liang et al., 2020; Martinez-Rovira et al., 2020; Meng et al., 2020; Roberts et al., 2020; Ullah et al., 2020; Wang H. et al., 2020; Wang X. et al., 2020; Xu et al., 2020; Zhu et al., 2020).

To date, several nanoparticles have shown to be effective in improving different aspects of traditional and novel cancer therapeutic approaches, to the point that several nanocarriers and nanoradiotherapy enhancers are being studied in phase II and III clinical trials (Maier-Hauff et al., 2007; Kim et al., 2010; Wegscheid et al., 2014; Cheng Y. et al., 2016; Shen et al., 2017; Yu et al., 2017; Hua et al., 2018; Daniel et al., 2019; Denora et al., 2019; Dufort et al., 2019; Kunoh et al., 2019; Luque-Michel et al., 2019; Rego et al., 2019, 2020; Ruan et al., 2019; Shi et al., 2019; 
TABLE 4 | Rational for a combinatorial approach using nanoparticles and stem cell therapy in malignant glioma.

\begin{tabular}{|c|c|}
\hline \multicolumn{2}{|c|}{ Rational for nanoparticle-based stem cell therapy in malignant glioma } \\
\hline \multirow[t]{3}{*}{ Drawbacks of using nanoparticles alone } & $\begin{array}{l}\text { - Big nanoparticles could be engulfed by the phagocytic mononuclear system (macrophages/lymphocytes) depending } \\
\text { on their size }\end{array}$ \\
\hline & - Necrotic central core and histological heterogeneity predispose to uneven intratumor biodistribution of nanoparticles \\
\hline & - Infiltrative cells leaving the tumor bulk are unlikely to be tracked by nanoparticles \\
\hline \multirow[t]{4}{*}{ Potential advantages of using combine therapy } & - Stem cells can transport bigger nanoparticles, increasing nanoparticle loading capacity \\
\hline & - Stem cells could transport big nanoparticles through the BBB \\
\hline & $\begin{array}{l}\text { - Stem cells could better deliver therapeutic nanoparticles into the hypoxic central glioma core where } \\
\text { treatment-resistant CSC locate }\end{array}$ \\
\hline & $\begin{array}{l}\text { - Stem cells could track and deliver their cargo to CSC leaving the tumor bulk. These CSC have been pinpointed as } \\
\text { culprits of future tumor recurrence }\end{array}$ \\
\hline
\end{tabular}

BBB, blood brain barrier; CSC, cancer stem cells.

Sousa et al., 2019; Ye et al., 2019; Zhang et al., 2019; Zhao et al., 2019; ZhuGe et al., 2019; Alves et al., 2020; Caban-Toktas et al., 2020; Chung et al., 2020; Ferreira et al., 2020; Kazmi et al., 2020; Liang et al., 2020; Martinez-Rovira et al., 2020; Meng et al., 2020; Roberts et al., 2020; Ullah et al., 2020; Wang H. et al., 2020; Wang X. et al., 2020; Xu et al., 2020; Zhu et al., 2020). In the next section, we will briefly review the role of nanoparticles as a standalone therapeutic approach for glioma tumors (Table 3), and then, we will review in detail the role of nanoparticles as a tool to further improve stem cell therapy (Table 4).

\section{Classification}

Nanoparticles can naturally occur in the environment mediated by biological or geological processes (Sharma et al., 2015), or as incidental by-product of human activities such as smelting or other processes involving the generation of metal fumes (Gonzalez-Pech et al., 2019). In addition, nanoparticles can be artificially synthetized and engineered (Kus et al., 2018). Given the wide variety of existing NPs, classification criteria are also abundant. We present the classification of NPs according to their origin and structure, as they will help understand the terminology used to describe NPs used in cancer research.

\section{Classification of Nanoparticles Based on Its Origin Organic}

Organic nanoparticles are based on natural compounds such as lipids, glycosides, peptides and others, as well as synthetic organic molecules (Romero and Moya, 2012; Tzeng et al., 2016; Kus et al., 2018; Karlsson et al., 2019; Kozielski et al., 2019; Tian et al., 2020). These organic elements can arrange themselves in threedimensional (3D) structures (Euliss et al., 2006), which is one of the main characteristics that differentiate organic from inorganic nanoparticles, as inorganic NPs do not form these 3D structures in any case (Romero and Moya, 2012). Furthermore, due to the weak interactions that hold many organic NPs together, they present a dynamic nature that allows, for example, for fusion and generation of larger structures depending on external conditions (Romero and Moya, 2012).

Organic nanoparticles display highly desirable characteristics in the biomedical field (Hussein Kamareddine et al., 2019). They have a dynamic nature and are able to respond to environmental variations in temperature, $\mathrm{pH}$, and UV radiation (Jagannathan et al., 2006; Affram et al., 2017; Hussein Kamareddine et al., 2019).
Furthermore, they can easily cross biological barriers and are considered less toxic due to its biodegradability; therefore, they are ideal as drug or gene delivery systems (Jagannathan et al., 2006; Hussein Kamareddine et al., 2019). Liposomes, vesicles, micelles, polymeric NPs, and dendrimers are all among the most common organic nanoparticles (for specific characteristic and applications, see Figure 1); however, among all of them, polymeric NPs are probably the most relevant in cancer research.

Polymeric NPs, also known as polymeric nanospheres, are commonly defined as solid polymer particles with matrix type structure, where a cargo can be embedded within the polymer matrix or included in the surface (Reis et al., 2006). Based on its origin, polymeric NPs can be classified as natural or synthetic. The first group contains NPs such as chitosan, which is a widely available natural cationic carbohydrate polymer approved by the Food and Drug Administration (FDA) and the European Medicines Agency (EMA) for drug and gene delivery and tissue engineering in humans (Lara-Velazquez et al., 2020). The second group, or synthetic polymer-based nanoparticles (SP-NPs), is the most relevant in medicine, as they can be easily synthesized and their properties can be tailored according to specific needs.

SP-NPs are prepared using synthetic polymers (Romero and Moya, 2012), which can be classified in polyesters such as poly(glycolic acid) (PGA), poly(lactic acid) (PLA), poly(caprolactone) (PCL), and poly(lactic-co-glycolic acid) or (PLGA); polyalkyl alcohols such as polyvinyl alcohol or PVA; and polyethers such as poly(ethylene glycol) (PEG) and poly(propylene glycol) (PPG) (Ranganathan et al., 2018). Currently, there are around 15 FDA-approved nanomedicines based on SP-NPs, 6 of them are used in cancer therapy (Bobo et al., 2016; Farjadian et al., 2019). Up to date, glioma research based on SP-NPs has been mainly focused on the development of more effective delivery systems, able to cross the blood brain barrier and specifically target the cancer cells (Ambruosi et al., 2006; Hua et al., 2011; Jiang et al., 2011; Guo et al., 2013; Bishop et al., 2016; Tzeng et al., 2016; Karlsson et al., 2019; Kozielski et al., 2019). This includes the generation of hybrid systems using booth synthetic polymers and natural compounds (Agrawal et al., 2015; Cook et al., 2015; Alex et al., 2016; Wang et al., 2017; Qi et al., 2020), as well as smart nanoparticles able to react according to the surrounded conditions or to specific stimulus (Soppimath et al., 2005; McNeeley et al., 2009; An et al., 2015; Mangraviti et al., 2015; Gao et al., 2016; Ye et al., 2019). 


\section{Nanoplatforms used as Nanocarriers in Cancer Therapy}

\begin{tabular}{|c|c|}
\hline Nanoplatforms & Features \\
\hline $100 n$ & $\begin{array}{l}\text { - } \\
\text { - Spherical polymeric vesicles } \\
\text { - } \quad \text { Ability to carry hydrophobic and hydrophilic molecules } \\
\text { - } \quad \text { Easily manipulated during their synthesis process }\left(\mathrm{T}^{\circ} \text { or } \mathrm{pH} \text { sensitive, to }\right. \\
\text { allow for controlled release) } \\
\text { - Long circulation time and good diffusion properties }\end{array}$ \\
\hline $20 \mathrm{~nm}$ - & $\begin{array}{l}\text { - Spherical polymeric vesicles that can be functionalized for better targeting } \\
\text { - } \quad \text { Shell is made of lipids or another amphiphilic material } \\
\text { - Hydrophobic interior and hydrophilic exterior (can carry protected insoluble } \\
\text { drugs/materials) } \\
\text { - Can be } \mathrm{T}^{\circ} \text { or } \mathrm{pH} \text { sensitive, to allow for controlled release }\end{array}$ \\
\hline $\begin{array}{c}\text { Polymeric } \\
\text { Nanoparticles }\end{array}$ & 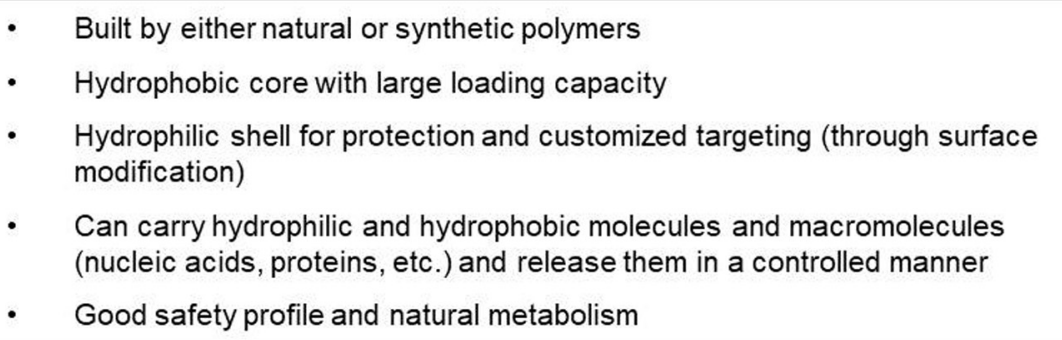 \\
\hline Dendrimers & $\begin{array}{l}\text { - Tree-like nanoparticle, containing extensive branching and multivalent } \\
\text { functional groups } \\
\text { - Can enclose different therapeutics inside its structure. } \\
\text { - } \quad \text { Can simultaneously contain imaging materials and targeting molecules } \\
\text { - By selecting a particular polymer, a controlled degradation of its branches } \\
\text { can regulate the release of the therapeutic molecules }\end{array}$ \\
\hline $\begin{array}{l}\text { Metal } \\
\text { Nanoparticles }\end{array}$ & $\begin{array}{l}\text { - Self-assembled of metallic atoms such as gold or iron (magnetic) } \\
\text { - Can be modified (through surface modifications) to achieve better targeting } \\
\text { - Gold: biologically inert } \rightarrow \text { low toxicity/high biocompatibility. Surface } \\
\text { plasmon resonance properties, so visible in the region of light spectrum } \\
\text { - Iron: strong magnetic properties } \rightarrow \text { allows for magnetic hyperthermia } \\
\text { (thermal ablation therapies) and advancing MRI imaging (supermagnetic } \\
\text { iron oxide nanoparticles (SPIONs)) }\end{array}$ \\
\hline $\begin{array}{c}\text { Carbon } \\
\text { Nanotubes }\end{array}$ & $\begin{array}{l}\text { - Carbone nanotubes (CNT) are allotropic form of carbons related to the } \\
\text { fullerene family, used in diagnosis and cancer treatment } \\
\text { - } \quad \text { High surface are but its needle shape allows for easily penetrate cells } \\
\text { - } \quad \text { Penetrate tumor by enhanced permeability and retention (EPR) } \\
\text { - } \quad \text { Exceptional thermal properties } \rightarrow \text { Thermal ablation (cancer treatment) } \\
\text { Good loading capacity (to carry chemotherapeutics). }\end{array}$ \\
\hline
\end{tabular}

Created with @BioRender-biorender.com 


\section{Inorganic}

Inorganic nanoparticles present unique physicochemical properties (optical, magnetic, etc.), inertness, high stability, and easy functionalization, which give them different advantages when compared to organic NPs. Due to their cellular internalization ability and low immunogenic response, these nanoparticles were initially used as drug and gene delivery systems (Xu et al., 2006; Evans et al., 2019). Different types of elements and inorganic compounds based on metals [metal NP $(\mathrm{mNP})]$, metalloids, or non-metals such as gold, silver, iron, magnesium, silicon, and others are differentially arranged and/or combined in order to display specific properties. Thus, there are some particular groups of NPs such as magnetic nanoparticles, which are usually based in a core of iron oxide $\mathrm{mNP}$ with a large magnetic momentum under an external magnetic field, which allow its use as MRI contrast enhancer and thermotherapy agents (Maier-Hauff et al., 2007; van Landeghem et al., 2009; Wegscheid et al., 2014). Plasmonic nanoparticles refer to mNPs such as gold $(\mathrm{Au})$ or silver $(\mathrm{Ag}) \mathrm{NPs}$ presenting with surface plasmon resonance (SPR), meaning that NP free electrons can be excited by electromagnetic fields (UV or infrared light) and resonate, creating the possibility to sense these changes (biosensors), produce heat (photothermal ablation/therapy), or create technologies such as surface-enhanced Raman spectroscopy (SERS) (Kaur et al., 2016; Chen et al., 2018; Liu et al., 2018). Quantum dots (Qdots) are another group of inorganic NPs, usually smaller than $50 \mathrm{~nm}$; these semiconductor NPs efficiently produce bioluminescence once excited by UV light, which has led them to be used in single cell and in vivo imaging ( $\mathrm{Xu}$ et al., 2006; Figure 1).

\section{Carbon Based}

These nanoparticles are predominantly composed by carbon, and their discovery revolutionized diverse scientific fields (Cha et al., 2013; Patel et al., 2019). Carbon-based nanomaterials have outstanding properties like high mechanical strength, thermoelectrical conductivity, and flexibility (Cha et al., 2013). These nanoparticles include fullerenes (carbon nanotubes), graphene, and nanodiamonds. Their broad range of properties makes these materials ideal imaging agents for tumor diagnosis (Patel et al., 2019; Figure 1).

\section{Classification of Nanoparticles Base on Their Structure}

\section{Single Nanoparticles}

Single nanoparticles are made of a single element such as gold, silver, copper, among others, and due to their homogeneity and electrochromic properties, they are widely used in electro-optical applications, energy conversion, and storage (Evans et al., 2019). Diverse systems for synchronized release of multiple drugs for cancer therapy have been designed based on single nanoparticles (Liao et al., 2014).

\section{Heterostructured Nanoparticles}

In an attempt to increase the performance and functionality of nanomaterials, heterostructured nanoparticles composed of two or more different materials were created. This technology allowed for the design of advanced NPs with additional properties arising from the synergy of the different materials (Wei and Zhao, 2016). One method to concrete this effort was to coat nanoparticles with one or more layers. Nanoparticles created in this way can be classified as core-shell (CS), when a central core (NP) is surrounded by one or more layers of different material [shell(s)], or as yolk-shell (YS). when the a movable core is located in a hollow cavity surrounded by a shell (Purbia and Paria, 2015). A hollow core-shell structure or hollow NP is another term referred to a NP without a core; the resulting empty space inside the shell can then be loaded with drugs, microRNA (miRNA), genes, peptides, and others that can now be released in a controlled manner. Janus nanoparticles are a different type of nanomaterials; they possess a tunable asymmetric structure; their surface has two or more regions with different properties, which confer them unique properties as selective reactivity or directional interactions. The field of application is broad and innovative including its use as sensors, self-propelled carriers, or coatings (Agrawal and Agrawal, 2019; Figure 2).

\section{Nanoparticles as a Theragnostic Approach in Glioma Nanoparticles as Radiosensitizers}

Cancer tumors frequently contain a chemo and/or radioresistant subpopulation that survives and proliferates after standard treatments, contributing to the recurrence of a more aggressive tumor (Dahan et al., 2014; Yuan et al., 2018). Cancer stem cells (CSCs) represent this treatment-resistant subpopulation, and huge efforts are being focused on developing strategies to make them more amenable to current and novel therapies. The use of radiosensitizers is a potential approach to overcome radioresistance; however, its principal shortcoming is the lack of target specificity, which may lead to low concentrations in tumor tissue and toxic effects in healthy cells.

In this regard, nanoparticles have been tested as radiosensitizers agents and also as radiosensitizers carriers, showing promising results after photon and particle radiation (Caban-Toktas et al., 2020; Chung et al., 2020; Kazmi et al., 2020). For instance, Kunoh et al. developed DNA-gold nanoparticles complexes to work as radiosensitizers; they showed good cellular targeting and being effective in inducing cell death by mitotic catastrophe in glioma CSC after X-ray irradiation (Kunoh et al., 2019). Kefayat et al. also described good performance of folic-acid-coated gold nanocluster in radiosensitizing orthotopic C6 glioma tumor in a murine model (Kefayat et al., 2019). Folic acid receptors are differentially expressed in the luminal side of cancerous blood-brain barrier (BBB) endothelial cells as well as in cancer cells but not in normal tissues, which explain the higher concentration of these NP in glioma tumor when compared to a healthy brain tissue (Kefayat et al., 2019).

Furthermore, in order to target the glioma-resistant population specifically located in the tumor hypoxic niche, Hua et al. developed hypoxia-responsive yolk-shell nanoparticles (liposomes) by encapsulating radiosensitizer hydrophobic drugs [aniopep-2-poly-(metronidazoles)n and doxorubicin (DOX)] in hydrophilic polymers (PEG2000); these NPs were functionalized to target gliomas cells and release its content only under hypoxic 


\section{Nanoparticles classification based on their Structure}

A

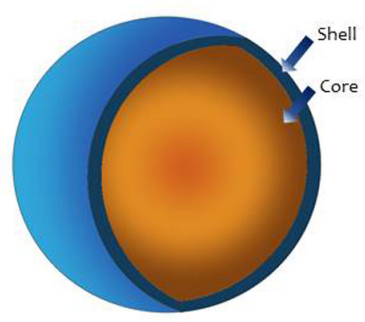

Core-Shell
B

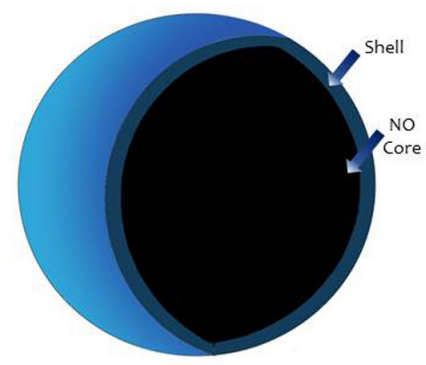

Hollow Core-Shell
C

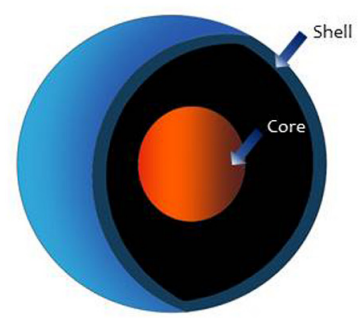

Yolk-Shell

FIGURE 2 | Nanoparticle classification based on its structure. (A) Core-shell (CS) nanoparticle (NP) possesses a central core (NP) surrounded by one or more layers of different material [shell(S)]. (B) Hollow core-shell structure or (hollow NP) refers to an NP without a core; the resulting empty space inside the shell can then be loaded with drugs, microRNA (miRNA), genes, peptides, and others that can now be released in a controlled manner. (C) Yolk-shell (YS) NP possesses a movable core that is located in a hollow cavity surrounded by a shell (Purbia and Paria, 2015).

conditions, increasing radiosensitization as shown in vitro and in vivo after systematic NP administration (Hua et al., 2018; Table 3).

\section{Nanoparticles as Nanocarriers}

The restricted permeability of the $\mathrm{BBB}$ has been one of the biggest challenges in the mission of effectively treating brain tumors. In nanomedicine, not all nanoparticles can efficiently cross this biological barrier despite their size and physicochemical characteristics; consequently, previously discussed strategies, such as ligand targeting, or improvements on the enhanced permeability and retention (EPR) effect are required.

While ligand targeting is an active targeting method and required NPs to be designed with this purpose in mind, EPR effect refers to a passive targeting mechanism common to all NPs. EPR effect relies on pathophysiological characteristics of tumor vs. healthy vessels as well as NP size, which is larger than individual conventional chemotherapeutics (usually $<1,000 \mathrm{Da}$ ). Due to their relatively larger size, NPs are not able to penetrate normal blood vessels but can easily cross diseased vessels such as those presented in brain tumors, leading to a selected distribution into cancer tissues. NP with diameters of at least 5-10 nm present reduced kidney excretion (by exceeding the clearance renal threshold of 40,000 Da), prolonged blood half-life, and better accumulation in the tissue of interest. For instance, the plasma half-life of doxorubicin increases from 5-10 min to 2-3 days when this is encapsulated into liposomes. In order to achieve better results from the application of organic nanoparticles such as liposomes, micelles, etc., some polymers such as PEG can be used to decrease NP aggregation and opsonization by plasma proteins, thus adding to the improved blood half-life (Hua et al., 2018).

Unfortunately, EPR effect is highly heterogeneous at inter- and intraindividual level, changing over time in the same tumor and even being dissimilar among different brain tumor lesions for the same patient. This, altogether, has led to clinical outcomes that does not match with preclinical results. In order to overcome these drawbacks, additional strategies to enhance $\mathrm{BBB}$ disruption and facilitate NP penetration have been applied. These strategies include pharmacological and physical methods such as sonoporation and radiation. Radiation can increase vascular permeability due to increased secretion of vascular endothelial growth factor (VEGF) and fibroblast growth factor (FGF) (Lee et al., 1995; Park et al., 2001). Thus, Lammers et al. (2007) showed a positive effect in the accumulation of DOXloaded polymeric NP sized between 5 and $10 \mathrm{~nm}$ (31 and $65 \mathrm{kDa}$, respectively) when tumors were primed with different doses of radiation.

Overall, all the previously described strategies should be carefully weighted when trying to optimize the use of nanoparticles as nanocarriers. In this setting, when applied to an orthotopic glioblastoma model, the use of functionalized biodegradable polymeric nanoparticles coated or loaded with anticancer drug has been able to confer longer survivals in preclinical models ( $\mathrm{Yu}$ et al., 2019). Among all the different nanocarriers (Figure 1), liposomes have been largely used. Preclinical studies using liposomes loaded with doxorubicin or coated with temozolomide showed higher concentrations of these drugs inside the brain when compared with the plasmatic levels; in these same models, survival benefit was also described (Zhao et al., 2018; Li et al., 2019). Noteworthy, liposomal doxorubicin has been clinically used in primary and recurrent high-grade glioma patients, and good biodistribution and decent outcomes were obtained; however, none of the studies were randomized controlled trials (RCTs) and were published just before or after the publication of the Stupp protocol (Fabel et al., 2001; Hau et al., 2004).

Overall, these results point the use of nanocarriers as a promising enhancer of effective therapies for the treatment of patients with glioma (Table 3 ). 


\section{Nanomachines}

Nanomachines or nanobots are molecular self-propelled nanodevices considered as smart delivery systems that respond to specific triggers (Khawaja, 2011; Jager and Giacomelli, 2015; Saxena et al., 2015; Fu et al., 2017). DNA nanorobots are nanometric devices controlled by an aptamer-encoded logic gate, able to sense specific stimulus such as intracellular $\mathrm{pH}$ or cell surface ligands in order to activate and reconfigure its structure for delivery of different payloads. Li et al. reported on a DNA nanorobot created through the DNA origami method; this was programmed to unfold itself upon binding to caveolin molecules expressed in cancerous blood vessel endothelial cells in order to deliver thrombin into tumor vessels. The authors were able to prove this concept in a murine model of breast cancer, successfully inducing intratumorally vascular thrombosis that resulted in tumor necrosis and growth tumor inhibition ( $\mathrm{Li}$ et al., 2018). This technology is revolutionizing the traditional way of treating different tumors and is a promising strategy to improve prognosis on brain tumor patients. Other novel approach introduced as a promising tool in the armamentarium for the treatment of glioma tumors is the use of stem cells. Along the next section, we will describe how the above-described nanotechnology has been coupled to engineer improved stem cell therapies for the treatment of brain cancer (Table 3).

\section{APPLICATIONS OF NANOPARTICLES IN STEM CELL GLIOMA THERAPY}

Nanomedicine has extend the reach to several cancer treatment approaches such as radiotherapy, chemotherapy, immunotherapy, and others. In the case of stem cell therapies, improvements in several aspects are clearly needed. In an attempt to consolidate the translational potential of this approach, nanoparticles have been used to enhance safety and efficacy, stem cell tumor homing, and in vivo tracking after stem cell delivery. On the other hand, apart from nanoparticle surface modifications performed in an attempt to improve pharmacokinetics and pharmacodynamics parameters, stem cells appear as a reasonable option to overcome the suboptimal penetration, distribution, and retention associated to some nanomaterials when used as therapeutic nanocarriers. The use of stem cells in this context definitely add another option for a more targeted nanoparticle delivery. Thus, the benefit obtained from this combined approach using nanoparticles and stem cells is bidirectional.

\section{Nanoparticles for Stem Cells Genetic Engineering}

Stem cells are known by their ability to serve as vehicles of antitumor cargoes. For this purpose, viral gene vectors have been traditionally used to transduce stem cells with a high degree of gene delivery efficiency resulting in constant payload production (anticancer proteins, cytokines, antibodies, viral vectors, etc.). Although newer generations of viral vectors present better safety profiles, these vectors have been associated with immunotoxicity as a response to viral proteins production or potential viral replication. They also would carry the hypothetical risk of uncontrolled viral genome integration and insertional mutagenesis, latent virus activation, and inflammatory responses leading to demyelination or neurodegeneration (Dewey et al., 1999; Mangraviti et al., 2016). In this setting, nanoparticlebased gene delivery represents an attractive non-viral strategy to bioengineer stem cells. Different from commercially available reagents such as Lipofectamine 2000 (Thermo Fisher Scientific, Waltham, MA) nanoparticles may represent a less toxic and more effective approach for gene delivery.

Our group reported on the use of biodegradable polymeric nanoparticles based on poly(beta-amino ester)s (PBAEs) to enable effective BMP4 gene delivery on human A-MSC, allowing for higher transfection rates than those of commercially available reagents. Transfected MSC retained their multipotency and their tumor-homing capacity and were functional, leading to extended survival in a rat orthotopic GBM model (Yong et al., 2009). Huang et al. also reported on the use of nanoparticles for stem cell bioengineering; using hyaluronic acid (HA)decorated superparamagnetic iron oxide nanoparticles as part of a magnetic ternary nanohybrid (MTN), the group was able to construct tumor necrosis factor-related apoptosis-inducing ligand (TRAIL)-secreting human mesenchymal stromal cell (hMSC). Decoration with CD44-binding HA and magnetic forces were used in this approach to increase cellular uptake of MTN. Impairment in tumor-homing properties were not observed (Huang R. Y. et al., 2019). Overall, nanoparticles raise as an option of safe and efficient gene delivery for stem cell; thus, helping stem cell therapy to achieve its maximal therapeutic potential.

\section{Nanoparticles as Stem Cells Payloads}

In the treatment of several malignancies, different nanoplatforms acting themselves as anticancer agents (Mooney et al., 2014a) or as carriers for these anticancer drugs (Mooney et al., 2014b) have been delivered locally and systemically. Recent advances in nanomedicine have allowed tuning nanoparticles properties in such a way that crossing the $\mathrm{BBB}$ and reaching brain tumors is now possible. However, there is a fine line between three factors: (1) the ideal size that a nanoparticle must have to easily cross the BBB (up to150 nm, optimal passage if < $15 \mathrm{~nm}$ ) (Gao and Jiang, 2006), (2) being big enough to still be able to carry enough payload, and (3) being small enough to avoid engulfment by the mononuclear phagocyte system but still contain all the necessary ligands to assure specific cancer targeting (Owens and Peppas, 2006).

Furthermore, even if researchers could secure that nanoparticles reach the glioma tumor bulk, there exist other potential drawbacks that are imperative to highlight; they are related to the presence and location of glioma cancer stem cells (1) Nanoparticles are neither able to track infiltrative glioma cells leaving the tumor bulk to colonize distal healthy brain parenchyma nor (2) to reach the necrotic glioma core where blood flow is impaired. These areas do not present an EPR effect, which would facilitate nanoparticles to distribute across other areas of the tumor. Allowing nanoparticles to access the hypoxic central core would be crucial, as the treatment-resistant 
subpopulation of glioma cancer cells would predominantly locate in that area (Table 4). Even after active targeting strategies including ligand targeting and microenvironment-related targeting (delivering payload depending on $\mathrm{pH}$, temperature, etc.) (Koo et al., 2006; Bernardi et al., 2008; Madhankumar et al., 2009; Hadjipanayis et al., 2010; Wang et al., 2011), nanoparticles alone are still insufficient and would be unlikely to overcome the above-mentioned roadblocks.

In this scenario, coupling stem cell therapy to nanotherapeutics offers the possibility to solve the previously stated dilemma regarding the inadequate distribution of therapeutic nanoparticles to the hypoxic glioma core and distant infiltrative tumor foci. Thus, stem cells could extend the reach for nanoparticles to penetrate these areas. This approach implies nanoparticles to be conjugated to stem cell surfaces or internalized before migrating toward malignant gliomas. Furthermore, the internalization of nanoparticles inside stem cells would allow them to be up to fivefold larger than the usual nanoparticles used in cancer therapy, without entailing problems in crossing the $\mathrm{BBB}$ or a higher risk to be engulfed by macrophages or lymphocytes (Koo et al., 2006; Bernardi et al., 2008; Madhankumar et al., 2009; Hadjipanayis et al., 2010; Wang et al., 2011). This increase in the nanoparticles' longitudinal size translates into an approximately 125-fold increase in the nanoparticle load potential (by a volume-based, three-dimensional factor of 5) (Koo et al., 2006; Bernardi et al., 2008; Madhankumar et al., 2009; Hadjipanayis et al., 2010; Wang et al., 2011).

In this same line, the Aboody group demonstrated that neural stem cells were able to improve intracranial nanoparticle retention and tumor-selective distribution in an in vivo model by coupling huge nanoparticles to NSC surface (Mooney et al., 2014b). Taking advantage from the significant differences in the environmental $\mathrm{pH}$ between tumor and healthy tissues, the Aboody group loaded FDAapproved NSC cell with $\mathrm{pH}$-sensitive doxorubicin-loaded mesoporous silica nanoparticles (MSN-Dox); the authors were able to tune nanoparticles properties to delay doxorubicin toxicity, allowing NSC to home into glioma tumors and deliver its payload only after arriving at the acidic tumor microenvironment. The approach led to a significant difference in survival when studied in a preclinical in vivo model (Cheng Y. et al., 2013). The same group also evaluated the role of NSC loaded with gold nanorods (AuNRs) to improve plasmonic photothermal therapy (aka thermal ablation), where the nanoparticles help to convert light into heat, aiming to eliminate cancerous tumor cells. The authors found that intratumor injections of AuNR-loaded NSC improved AuNRs distribution inside the tumor bulk when compared to locally injected free AuNRs in a brain metastasis heterotopic in vivo model (Mooney et al., 2014a).

The role of mesenchymal stem cells as nanoparticle carriers has also been investigated. Polymeric nanoparticles (paclitaxel-encapsulated PLGA nanoparticles) were loaded into BM-MSC. Osteogenesis, adipogenesis (chondrogenesis was not evaluated), and tumor homing were not affected by nanoparticle inclusion. The approach was associated with improved survival in a rat orthotopic glioma model when the modified MSCs were injected in the contralateral hemisphere (Wang et al., 2018). A similar approach to the one described by the Aboody group was performed on modified MSCs by loading them with gold nanoparticles (nanostarts) to improve phototherapy. Although studied in a heterotopic model of prostate cancer, the results support the use of MSC to maximize clinically relevant gold nanoparticles' optical-electronic properties by increasing nanoparticle intratumor distribution (Huang L. et al., 2019).

\section{Nanoparticles to Modulate Stem Cell Tumor Homing}

Several tumor cytokines and stem cells surface proteins have been involved in enhancing MSC migration toward glioma tumors; however, no specific mechanism has been described yet. Tumor cytokines such as endothelial cell growth factor (EGF), platelet-derived growth factor (PDGF), VEGF, tumor growth factor $\beta 1$ (TGF- $\beta 1$ ), interleukin 8 (IL-8), monocyte chemoattractant protein-1 (MCP-1), and stromal cellderived factor 1 alpha (SDF-1 $\alpha$ ) as well as stem cells surface proteins such as CD44, CXC chemokine receptor 4 (CXCR4 ), integrin $\alpha 4$, and TGF- $\beta$ receptors have been associated with increased MSC homing in gliomas (Young et al., 2014; Yamazoe et al., 2015).

The impact on stem cell behavior after being loaded with nanoparticles for different purposes has not been the principal focus of research. However, there already exist reports describing the increase in migration toward cancer cells after loading hMSC with iron oxide nanoparticles. This would be related to the overexpression of EGFR observed after nanoparticle inclusion and the characteristic elevated production of EGF by colon cancer cells used in the in vitro Boyden chamber experiments (Chung et al., 2011). Interestingly, the same trend has been observed when human BM-MSC were labeled with ferucarbotran nanoparticles and protamine. Using cellular magnetic resonance imagining (MRI) to track the labeled stem cells, increased BM-MSC migration toward in vitro and in vivo glioma models was found, and the SDF-1/CXCR4 signaling axis was associated to this phenomenon (Chien et al., 2011).

\section{Nanoparticles for Tracking Stem Cells During Glioma Therapy}

Stem-cell-based therapies rely on the ability of the grafted cells to target the organ of interest. In case of malignant gliomas, it is crucial to ensure stem cell tumor homing. In the preclinical setting, conventional methods for tracking migration and final fade of stem cells are traditionally based on bioluminescence imaging; however, poor spatial distribution and lack of translational applicability made necessary to establish a reasonably translational method that can be easily applied in a clinical setup. 
Cellular MRI-based tracking technologies have risen as gold standard for non-invasive, real-time monitoring of transplanted stem cells (Kim et al., 2011). This approach would allow the study of stem cell biodistribution, migration, survival, and even differentiation with high spatial resolution and without the need for ionizing radiation. To make this possible, stem cells will require being labeled with magnetic nanoparticles. Although several options exit, magnetic iron oxide nanoparticles such superparamagnetic iron oxide nanoparticles (SPIONs) have been commonly used for this purpose (Cromer Berman et al., 2011).

The conjugation of stem cells and SPIONs has allowed for tracking MSC migration and homing into glioma tumors in a rodent glioma model without compromising such migratory capacity (Wu et al., 2008; Menon et al., 2012). NSCs have also been widely studied in this regard (Spina et al., 1975; Neri et al., 2008). After 1 month of follow-up, it was demonstrated that SPIONs would not impair multipotency, cell survival, or proliferation (Agha-Hosseini et al., 2010). Furthermore, a NSC migration speed of $50-70 \mu \mathrm{m} /$ day has been calculated after the cells were loaded with ferumoxide (SPION + dextran) (Flexman et al., 2011). Clinically relevant results were those presented by Thu et al. The group showed that loading FDA-approved NSC with ferumoxide-protamine complex nanoparticles did not impaired humor-homing properties in a murine glioma model (Thu et al., 2009; Auffinger et al., 2013). Gutova et al. also reported on similar findings when using ultrasmall superparamagnetic iron oxide nanoparticles (USPIONs) in clinically graded nanoparticles and FDA-approved NSC (Gutova et al., 2013). Currently, different complementary imaging modalities and nanoparticles stem-cell coupling techniques are being studied (Egawa et al., 2015; Cheng S. H. et al., 2016; Qiao et al., 2018).

Even when this approach was first evaluated in the clinical setting around 2006 (Zhu et al., 2006) and has been used in different pathologies and other cancers (de Vries et al., 2005), glioma patients have not yet harnessed the benefit of the clinical applicability of this technology. This could be related to the difficulties in obtaining long-term follow-up of nanoparticlelabeled stem cells, as their self-renewal capacity render less nanoparticle concentration through each replicative cell cycle.

\section{CHALLENGE, POTENTIAL PITFALLS, AND FUTURE PERSPECTIVE}

Challenge and pitfalls associated with this relatively novel approach is proper of any disruptive technology. The ethical concerns associated with the use of particular stem cells, while seemingly addressed with modern techniques, need to be further discussed before extensive use can be assumed

\section{REFERENCES}

Aboody, K. S., Brown, A., Rainov, N. G., Bower, K. A., Liu, S., Yang, W., et al. (2000). Neural stem cells display extensive tropism for pathology in adult brain: evidence from intracranial gliomas. Proc.
(Ramos-Zúñiga et al., 2012). Clinical endeavors utilizing stem cells as potential therapeutic tools in glioma patients have already glimpsed relative success. In this setting, careful and individualized selection of specific types of stem cell will be key in in future clinical applications for these patients. For instance, we concentrate our efforts in the application of adiposederived MSCs, which can be easily obtained from the same patient. Although still in preclinical phase, we expect them to be rapidly bioengineered and used for autologous transplantation, thus allowing for an individualized and expedited process so the patients can therapeutically receive them even at time of surgery.

The introduction of the nanotechnology in stem cell therapies has shown to be beneficial and hopefully will keep turning stem cell therapies into a less worrisome and more controlled therapeutic strategy. To date, we have explored NP for stem cell bioengineering and cell tracking; however, we believe that their malleability allows for further uses such as the ones previously described, alone or in combination, and even for stem cell functionalization (Kim et al., 2011; Bishop et al., 2016; Mangraviti et al., 2016; Wilson et al., 2017a,b; Tian et al., 2020).

Finally, the combination of these therapies should not be limited to only nanoparticles and stem cells; this combined approach will need to explore if further value can be obtained by coupling with additional fields such as radiotherapy, thermotherapy, targeted systemic therapies, focused ultrasound, and other novel diagnostic techniques such as ultrahigh magnetic strength imaging and novel radiotracers in order to maximize its benefits.

\section{AUTHOR CONTRIBUTIONS}

HR-G and KA-E screened titles for relevance and abstracted the data from the eligible full text articles. SK, AQ-H, and DT critically revised the manuscript with input from the entire team. HR-G and KA-E created the figures and tables. HR-G, KA-E, and DT worked on study conception and design. All authors analyzed and interpreted the data, drafted the manuscript, and read and approved the final draft.

\section{FUNDING}

This publication was made possible through the support of the Eveleigh Family Career Development Award for Cancer Research at Mayo Clinic in Florida. AQ-H was supported by the Mayo Clinic Professorship, the Mayo Clinic Clinician Investigator award, the Florida Department of Health Cancer Research Chair Fund, and the NIH (R43CA221490, R01CA200399, R01CA195503, and R01CA216855).

Natl. Acad. Sci. U.S.A. 97, 12846-12851. doi: 10.1073/pnas.97.23. 12846

Affram, K., Udofot, O., Singh, M., Krishnan, S., Reams, R., Rosenberg, J., et al. (2017). Smart thermosensitive liposomes for effective solid tumor therapy and in vivo imaging. PLoS One 12:e0185116. doi: 10.1371/journal.pone.0185116 
Agha-Hosseini, F., Jahani, M. A., Jahani, M., Mirzaii-Dizgah, I., and AliMoghaddam, K. (2010). In vitro isolation of stem cells derived from human dental pulp. Clin. Transplant. 24, E23-E28.

Agrawal, G., and Agrawal, R. (2019). Janus nanoparticles: recent advances in their interfacial and biomedical applications. ACS Appl. Nano Mater. 2, 1738-1757. doi: 10.1021/acsanm.9b00283

Agrawal, U., Chashoo, G., Sharma, P. R., Kumar, A., Saxena, A. K., and Vyas, S. P. (2015). Tailored polymer-lipid hybrid nanoparticles for the delivery of drug conjugate: dual strategy for brain targeting. Colloids Surf. B Biointerfaces 126, 414-425. doi: 10.1016/j.colsurfb.2014.12.045

Alex, A. T., Joseph, A., Shavi, G., Rao, J. V., and Udupa, N. (2016). Development and evaluation of carboplatin-loaded PCL nanoparticles for intranasal delivery. Drug Deliv. 23, 2144-2153. doi: 10.3109/10717544.2014.948643

Allahverdi, A., Arefian, E., Soleimani, M., Ai, J., Nahanmoghaddam, N., Yousefi-Ahmadipour, A., et al. (2020). MicroRNA-4731-5p delivered by ADmesenchymal stem cells induces cell cycle arrest and apoptosis in glioblastoma. J. Cell. Physiol. 235, 8167-8175. doi: 10.1002/jcp.29472

Altanerova, V., Cihova, M., Babic, M., Rychly, B., Ondicova, K., Mravec, B., et al. (2012). Human adipose tissue-derived mesenchymal stem cells expressing yeast cytosinedeaminase::uracil phosphoribosyltransferase inhibit intracerebral rat glioblastoma. Int. J. Cancer 130, 2455-2463. doi: 10.1002/ijc.26278

Alves, S. R., Colquhoun, A., Wu, X. Y., and de Oliveira Silva, D. (2020). Synthesis of terpolymer-lipid encapsulated diruthenium(II,III)-anti-inflammatory metallodrug nanoparticles to enhance activity against glioblastoma cancer cells. J. Inorg. Biochem. 205:110984. doi: 10.1016/j.jinorgbio.2019.110984

Amano, S., Gu, C., Koizumi, S., Tokuyama, T., and Namba, H. (2011). Timing of ganciclovir administration in glioma gene therapy using HSVtk genetransduced mesenchymal stem cells. Cancer Genom. Proteomics 8, 245-250.

Ambruosi, A., Gelperina, S., Khalansky, A., Tanski, S., Theisen, A., and Kreuter, J. (2006). Influence of surfactants, polymer and doxorubicin loading on the antitumour effect of poly(butyl cyanoacrylate) nanoparticles in a rat glioma model. J. Microencapsul. 23, 582-592. doi: 10.1080/02652040600788080

An, S., He, D., Wagner, E., and Jiang, C. (2015). Peptide-like polymers exerting effective glioma-targeted siRNA delivery and release for therapeutic application. Small 11, 5142-5150. doi: 10.1002/smll.201501167

Andres, M., Bratt-Leal, A. Z., Wang, Y., and Loring, J. F. (2019). "Induced pluripotent stem cels," in Principles of Regenerative Medicine. 3rd Edition ed, ed. A. Atala (Amsterdam: ElSevier).

Auffinger, B., Morshed, R., Tobias, A., Cheng, Y., Ahmed, A. U., and Lesniak, M. S. (2013). Drug-loaded nanoparticle systems and adult stem cells: a potential marriage for the treatment of malignant glioma? Oncotarget 4, 378-396. doi: 10.18632/oncotarget.937

Balyasnikova, I. V., Ferguson, S. D., Han, Y., Liu, F., and Lesniak, M. S. (2011). Therapeutic effect of neural stem cells expressing TRAIL and bortezomib in mice with glioma xenografts. Cancer Lett. 310, 148-159. doi: 10.1016/j.canlet. 2011.06.029

Balyasnikova, I. V., Prasol, M. S., Ferguson, S. D., Han, Y., Ahmed, A. U., Gutova, M., et al. (2014). Intranasal delivery of mesenchymal stem cells significantly extends survival of irradiated mice with experimental brain tumors. Mol. Ther. 22, 140-148. doi: 10.1038/mt.2013.199

Behnan, J., Isakson, P., Joel, M., Cilio, C., Langmoen, I. A., Vik-Mo, E. O., et al. (2014). Recruited brain tumor-derived mesenchymal stem cells contribute to brain tumor progression. Stem Cells 32, 1110-1123. doi: 10.1002/stem.1614

Beier, D., Hau, P., Proescholdt, M., Lohmeier, A., Wischhusen, J., Oefner, P. J., et al. (2007). CD133(+) and CD133(-) glioblastoma-derived cancer stem cells show differential growth characteristics and molecular profiles. Cancer Res. 67, 4010-4015. doi: 10.1158/0008-5472.can-06-4180

Benedetti, S., Pirola, B., Pollo, B., Magrassi, L., Bruzzone, M. G., Rigamonti, D., et al. (2000). Gene therapy of experimental brain tumors using neural progenitor cells. Nat Med. 6, 447-450. doi: 10.1038/74710

Bernardi, R. J., Lowery, A. R., Thompson, P. A., Blaney, S. M., and West, J. L. (2008). Immunonanoshells for targeted photothermal ablation in medulloblastoma and glioma: an in vitro evaluation using human cell lines. J. Neuro Oncol. 86, 165-172. doi: 10.1007/s11060-007-9467-3

Bishop, C. J., Majewski, R. L., Guiriba, T. R., Wilson, D. R., Bhise, N. S., QuiñonesHinojosa, A., et al. (2016). Quantification of cellular and nuclear uptake rates of polymeric gene delivery nanoparticles and DNA plasmids via flow cytometry. Acta Biomater. 37, 120-130. doi: 10.1016/j.actbio.2016.03.036
Bobo, D., Robinson, K. J., Islam, J., Thurecht, K. J., and Corrie, S. R. (2016). Nanoparticle-based medicines: a review of FDA-approved materials and clinical trials to date. Pharm. Res. 33, 2373-2387. doi: 10.1007/s11095-0161958-5

Brandes, A. A., Tosoni, A., Franceschi, E., Sotti, G., Frezza, G., Amistà, P., et al. (2009). Recurrence pattern after temozolomide concomitant with and adjuvant to radiotherapy in newly diagnosed patients with glioblastoma: correlation With MGMT promoter methylation status. J. Clin. Oncol. 27, 1275-1279. doi: 10.1200/jco.2008.19.4969

Breznik, B., Motaln, H., Vittori, M., Rotter, A., and Lah Turnsek, T. (2017). Mesenchymal stem cells differentially affect the invasion of distinct glioblastoma cell lines. Oncotarget 8, 25482-25499. doi: 10.18632/oncotarget. 16041

Brown, A. B., Yang, W., Schmidt, N. O., Carroll, R., Leishear, K. K., Rainov, N. G., et al. (2003). Intravascular delivery of neural stem cell lines to target intracranial and extracranial tumors of neural and non-neural origin. Hum. Gene Ther. 14, 1777-1785. doi: 10.1089/104303403322611782

Bryukhovetskiy, I. S., Mischenko, P. V., Tolok, E. V., Zaitcev, S. V., Khotimchenko, Y. S., and Bryukhovetskiy, A. S. (2015). Directional migration of adult hematopoeitic progenitors to C6 glioma in vitro. Oncol. Lett. 9, 1839-1844. doi: $10.3892 / \mathrm{ol} .2015 .2952$

Caban-Toktas, S., Sahin, A., Lule, S., Esendagli, G., Vural, I., Karli Oguz, K., et al. (2020). Combination of Paclitaxel and R-flurbiprofen loaded PLGA nanoparticles suppresses glioblastoma growth on systemic administration. Int. J. Pharm. 578:119076. doi: 10.1016/j.ijpharm.2020.119076

Caccese, M., Padovan, M., D’Avella, D., Chioffi, F., Gardiman, M. P., Berti, F., et al. (2020). Anaplastic Astrocytoma: State of the art and future directions. Crit. Rev. Oncol. Hematol. 153:103062. doi: 10.1016/j.critrevonc.2020.103062

Cantrell, J. N., Waddle, M. R., Rotman, M., Peterson, J. L., Ruiz-Garcia, H. Heckman, M. G., et al. (2019). Progress toward long-term survivors of glioblastoma. Mayo Clin. Proc. 94, 1278-1286. doi: 10.1016/j.mayocp.2018.11. 031

Cha, C. Y., Shin, S. R., Annabi, N., Dokmeci, M. R., and Khademhosseini, A (2013). Carbon-based nanomaterials: multifunctional materials for biomedical engineering. ACS Nano 7, 2891-2897. doi: 10.1021/nn401196a

Chaichana, K. L., Cabrera-Aldana, E. E., Jusue-Torres, I., Wijesekera, O., Olivi, A., Rahman, M., et al. (2014a). When gross total resection of a glioblastoma is possible, how much resection should be achieved? World Neurosurg. 82, e257-e265.

Chaichana, K. L., Jusue-Torres, I., Lemos, A. M., Gokaslan, A., Cabrera-Aldana, E. E., Ashary, A., et al. (2014b). The butterfly effect on glioblastoma: is volumetric extent of resection more effective than biopsy for these tumors? J. Neuro Oncol. 120, 625-634. doi: 10.1007/s11060-014-1597-9

Chaichana, K. L., Jusue-Torres, I., Navarro-Ramirez, R., Raza, S. M., PascualGallego, M., Ibrahim, A., et al. (2014c). Establishing percent resection and residual volume thresholds affecting survival and recurrence for patients with newly diagnosed intracranial glioblastoma. Neuro Oncol. 16, 113-122. doi: $10.1093 /$ neuonc/not 137

Chamberlain, M. C. (2011). Radiographic patterns of relapse in glioblastoma. J. Neuro Oncol. 101, 319-323. doi: 10.1007/s11060-010-0251-4

Chen, Y., Bian, X., Aliru, M., Deorukhkar, A. A., Ekpenyong, O., Liang, S., et al. (2018). Hypoxia-targeted gold nanorods for cancer photothermal therapy. Oncotarget 9, 26556-26571.

Chen, Y. T., Wei, J. D., Wang, J. P., Lee, H. H., Chiang, E. R., Lai, H. C., et al. (2011). Isolation of mesenchymal stem cells from human ligamentum flavum: implicating etiology of ligamentum flavum hypertrophy. Spine 36, E1193-E1200.

Cheng, L., Huang, Z., Zhou, W., Wu, Q., Donnola, S., Liu, J. K., et al. (2013). Glioblastoma stem cells generate vascular pericytes to support vessel function and tumor growth. Cell 153, 139-152. doi: 10.1016/j.cell.2013.02.021

Cheng, S. H., Yu, D., Tsai, H. M., Morshed, R. A., Kanojia, D., Lo, L. W., et al. (2016). Dynamic in vivo SPECT imaging of neural stem cells functionalized with radiolabeled nanoparticles for tracking of glioblastoma. J. Nuclear Med. 57, 279-284. doi: 10.2967/jnumed.115.163006

Cheng, Y., Morshed, R., Cheng, S. H., Tobias, A., Auffinger, B., Wainwright, D. A., et al. (2013). Nanoparticle-programmed self-destructive neural stem cells for glioblastoma targeting and therapy. Small 9, 4123-4129. doi: 10.1002/smll. 201301111 
Cheng, Y., Muroski, M. E., Petit, D., Mansell, R., Vemulkar, T., Morshed, R. A., et al. (2016). Rotating magnetic field induced oscillation of magnetic particles for in vivo mechanical destruction of malignant glioma. J. Control Release 223, 75-84. doi: 10.1016/j.jconrel.2015.12.028

Chien, L. Y., Hsiao, J. K., Hsu, S. C., Yao, M., Lu, C. W., Liu, H. M., et al. (2011). In vivo magnetic resonance imaging of cell tropism, trafficking mechanism, and therapeutic impact of human mesenchymal stem cells in a murine glioma model. Biomaterials 32, 3275-3284. doi: 10.1016/j.biomaterials.2011.01.042

Choi, S. A., Hwang, S. K., Wang, K. C., Cho, B. K., Phi, J. H., Lee, J. Y., et al. (2011). Therapeutic efficacy and safety of TRAIL-producing human adipose tissue-derived mesenchymal stem cells against experimental brainstem glioma. Neuro Oncol. 13, 61-69. doi: 10.1093/neuonc/noq147

Chung, K., Ullah, I., Kim, N., Lim, J., Shin, J., Lee, S. C., et al. (2020). Intranasal delivery of cancer-targeting doxorubicin-loaded PLGA nanoparticles arrests glioblastoma growth. J. Drug Target. 28, 617-626. doi: 10.1080/1061186x.2019. 1706095

Chung, T. H., Hsiao, J. K., Hsu, S. C., Yao, M., Chen, Y. C., Wang, S. W., et al. (2011). Iron oxide nanoparticle-induced epidermal growth factor receptor expression in human stem cells for tumor therapy. ACS Nano 5, 9807-9816. doi: $10.1021 / \mathrm{nn} 2033902$

Cook, R. L., Householder, K. T., Chung, E. P., Prakapenka, A. V., DiPerna, D. M., and Sirianni, R. W. (2015). A critical evaluation of drug delivery from ligand modified nanoparticles: confounding small molecule distribution and efficacy in the central nervous system. J. Control. Release 220(Pt A), 89-97. doi: 10. 1016/j.jconrel.2015.10.013

Cromer Berman, S. M., Walczak, P., and Bulte, J. W. (2011). Tracking stem cells using magnetic nanoparticles. Wiley Interdiscip. Rev. Nanomed. Nanobiotechnol. 3, 343-355. doi: 10.1002/wnan.140

Dahan, P., Gala, J. M., Delmas, C., Monferran, S., Malric, L., Zentkowski, D., et al. (2014). Ionizing radiations sustain glioblastoma cell dedifferentiation to a stemlike phenotype through survivin: possible involvement in radioresistance. Cell Death Dis. 5:e1543. doi: 10.1038/cddis.2014.509

Daniel, J., Montaleytang, M., Nagarajan, S., Picard, S., Clermont, G., Lazar, A. N., et al. (2019). Hydrophilic fluorescent nanoprodrug of paclitaxel for glioblastoma chemotherapy. ACS Omega 4, 18342-18354. doi: 10.1021/ acsomega.9b02588

de Melo, S. M., Bittencourt, S., Ferrazoli, E. G., da Silva, C. S., da Cunha, F. F., da Silva, F. H., et al. (2015). The anti-tumor effects of adipose tissue mesenchymal stem cell transduced with HSV-Tk Gene on U-87driven brain tumor. PLoS One 10:e128922. doi: 10.1371/journal.pone.01 28922

de Vries, I. J., Lesterhuis, W. J., Barentsz, J. O., Verdijk, P., van Krieken, J. H., Boerman, O. C., et al. (2005). Magnetic resonance tracking of dendritic cells in melanoma patients for monitoring of cellular therapy. Nat. Biotechnol. 23, 1407-1413. doi: 10.1038/nbt1154

Denora, N., Lee, C., Iacobazzi, R. M., Choi, J. Y., Song, I. H., Yoo, J. S., et al. (2019). TSPO-targeted NIR-fluorescent ultra-small iron oxide nanoparticles for glioblastoma imaging. Eur. J. Pharm. Sci. 139:105047. doi: 10.1016/j.ejps.2019. 105047

Dewey, R. A., Morrissey, G., Cowsill, C. M., Stone, D., Bolognani, F., Dodd, N. J., et al. (1999). Chronic brain inflammation and persistent herpes simplex virus 1 thymidine kinase expression in survivors of syngeneic glioma treated by adenovirus-mediated gene therapy: implications for clinical trials. Nat. Med. 5, 1256-1263. doi: 10.1038/15207

Dominici, M., Le Blanc, K., Mueller, I., Slaper-Cortenbach, I., Marini, F., Krause, D., et al. (2006). Minimal criteria for defining multipotent mesenchymal stromal cells. the international society for cellular therapy position statement. Cytotherapy 8, 315-317. doi: 10.1080/146532406008 55905

Drumm, M. R., Dixit, K. S., Grimm, S., Kumthekar, P., Lukas, R. V., Raizer, J. J., et al. (2019). Extensive brainstem infiltration, not mass effect, is a common feature of end-stage cerebral glioblastomas. Neuro Oncol. 22, 470-479. doi: 10.1093/neuonc/noz216

Dufort, S., Appelboom, G., Verry, C., Barbier, E. L., Lux, F., Brauer-Krisch, E., et al. (2019). Ultrasmall theranostic gadolinium-based nanoparticles improve highgrade rat glioma survival. J. Clin. Neurosci. 67, 215-219. doi: 10.1016/j.jocn. 2019.05.065
Egawa, E. Y., Kitamura, N., Nakai, R., Arima, Y., and Iwata, H. (2015). A DNA hybridization system for labeling of neural stem cells with SPIO nanoparticles for MRI monitoring post-transplantation. Biomaterials 54, 158-167. doi: 10. 1016/j.biomaterials.2015.03.017

Ehtesham, M., Kabos, P., Kabosova, A., Neuman, T., Black, K. L., and Yu, J. S. (2001). The use of interleukin 12-secreting neural stem cells for the treatment of intracranial glioma. Cancer Res. 62, 5657-5663.

Erices, A., Conget, P., and Minguell, J. J. (2000). Mesenchymal progenitor cells in human umbilical cord blood. Br. J. Haematol. 109, 235-242. doi: 10.1046/ j.1365-2141.2000.01986.x

Euliss, L. E., DuPont, J. A., Gratton, S., and DeSimone, J. (2006). Imparting size, shape, and composition control of materials for nanomedicine. Chem. Soc. Rev. 35, 1095-1104. doi: 10.1039/b600913c

European Commission (2011). Commission Recommendation of 18 October 2011 on the definition of nanomaterial 2011/696/EU. Off. J. Eur. Union 275, 38-40.

Evans, R. C., Ellingworth, A., Cashen, C. J., Weinberger, C. R., and Sambur, J. B. (2019). Influence of single-nanoparticle electrochromic dynamics on the durability and speed of smart windows. Proc. Natl. Acad. Sci. U.S.A. 116, 12666-12671. doi: 10.1073/pnas.1822007116

Fabel, K., Dietrich, J., Hau, P., Wismeth, C., Winner, B., Przywara, S., et al. (2001). Long-term stabilization in patients with malignant glioma after treatment with liposomal doxorubicin. Cancer 92, 1936-1942. doi: 10.1002/10970142(20011001)92:7<1936::aid-cncr1712>3.0.co;2-h

Farjadian, F., Ghasemi, A., Gohari, O., Roointan, A., Karimi, M., and Hamblin, M. R. (2019). Nanopharmaceuticals and nanomedicines currently on the market: challenges and opportunities. Nanomedicine 14, 93-126. doi: 10.2217/ nnm-2018-0120

Ferreira, N. N., Granja, S., Boni, F. I., Ferreira, L. M. B., Reis, R. M., Baltazar, F., et al. (2020). A novel strategy for glioblastoma treatment combining alpha-cyano4-hydroxycinnamic acid with cetuximab using nanotechnology-based delivery systems. Drug Deliv. Transl. Res. 10, 594-609. doi: 10.1007/s13346-02000713-8

Flexman, J. A., Cross, D. J., Tran, L. N., Sasaki, T., Kim, Y., and Minoshima, S. (2011). Quantitative analysis of neural stem cell migration and tracer clearance in the rat brain by MRI. Mol. Imaging Biol. 13, 104-111. doi: 10.1007/s11307010-0311-3

Friedenstein, A. J., Chailakhjan, R. K., and Lalykina, K. S. (1970). The development of fibroblast colonies in monolayer cultures of guinea-pig bone marrow and spleen cells. Cell Tissue Kinet. 3, 393-403. doi: 10.1111/j.1365-2184.1970. tb00347.x

Friedenstein, A. J., Chailakhyan, R. K., Latsinik, N. V., Panasyuk, A. F., and Keiliss-Borok, I. V. (1974). Stromal cells responsible for transferring the microenvironment of the hemopoietic tissues. Cloning in vitro and retransplantation in vivo. Transplantation 17,331-340. doi: 10.1097/00007890197404000-00001

Friedenstein, A. J., Petrakova, K. V., Kurolesova, A. I., and Frolova, G. P. (1968). Heterotopic of bone marrow. Analysis of precursor cells for osteogenic and hematopoietic tissues. Transplantation 6, 230-247.

Fu, J. L., Stankeviciute, G., Oh, S. W., Collins, J., Zhong, Y. H., and Zhang, T. (2017). Self-assembled nucleic acid nanostructures for cancer theranostic medicines. Curr. Top. Med. Chem. 17, 1815-1828. doi: 10.2174/ 1568026617666161122115722

Galli, R., Binda, E., Orfanelli, U., Cipelletti, B., Gritti, A., De Vitis, S., et al. (2004). Isolation and characterization of tumorigenic, stem-like neural precursors from human glioblastoma. Cancer Res. 64, 7011-7021. doi: 10.1158/0008-5472.can04- 1364

Gao, K., and Jiang, X. (2006). Influence of particle size on transport of methotrexate across blood brain barrier by polysorbate 80 -coated polybutylcyanoacrylate nanoparticles. Int. J. Pharm. 310, 213-219. doi: 10.1016/j.ijpharm.2005.11.040

Gao, S., Tian, H., Xing, Z., Zhang, D., Guo, Y., Guo, Z., et al. (2016). A non-viral suicide gene delivery system traversing the blood brain barrier for non-invasive glioma targeting treatment. J. Control. Release 243, 357-369. doi: 10.1016/j. jconrel.2016.10.027

Girdlestone, J., Limbani, V. A., Cutler, A. J., and Navarrete, C. V. (2009). Efficient expansion of mesenchymal stromal cells from umbilical cord under low serum conditions. Cytotherapy 11, 738-748. doi: 10.3109/14653240903079401 
Golombek, S. K., May, J. N., Theek, B., Appold, L., Drude, N., Kiessling, F., et al. (2018). Tumor targeting via EPR: strategies to enhance patient responses. $A d v$. Drug Deliv. Rev. 130, 17-38. doi: 10.1016/j.addr.2018.07.007

Gonzalez-Pech, N. I., Stebounova, L. V., Ustunol, I. B., Park, J. H., Renee Anthony, T., Peters, T. M., et al. (2019). Size, composition, morphology, and health implications of airborne incidental metal-containing nanoparticles. J. Occup. Environ. Hygiene 16, 387-399. doi: 10.1080/15459624.2018.15 59925

Guo, K. T., Fu, P., Juerchott, K., Motaln, H., Selbig, J., Lah, T., et al. (2014). The expression of Wnt-inhibitor DKK1 (Dickkopf 1) is determined by intercellular crosstalk and hypoxia in human malignant gliomas. J. Cancer Res. Clin. Oncol. 140, 1261-1270. doi: 10.1007/s00432-014-1642-2

Guo, W., Li, A., Jia, Z., Yuan, Y., Dai, H., and Li, H. (2013). Transferrin modified PEG-PLA-resveratrol conjugates: in vitro and in vivo studies for glioma. Eur. J. Pharmacol. 718, 41-47. doi: 10.1016/j.ejphar.2013.09.034

Gutova, M., Frank, J. A., D’Apuzzo, M., Khankaldyyan, V., Gilchrist, M. M., Annala, A. J., et al. (2013). Magnetic resonance imaging tracking of ferumoxytol-labeled human neural stem cells: studies leading to clinical use. Stem Cells Transl. Med. 2, 766-775. doi: 10.5966/sctm.2013-0049

Hadjipanayis, C. G., Machaidze, R., Kaluzova, M., Wang, L., Schuette, A. J., Chen, H., et al. (2010). EGFRvIII antibody-conjugated iron oxide nanoparticles for magnetic resonance imaging-guided convection-enhanced delivery and targeted therapy of glioblastoma. Cancer Res. 70, 6303-6312. doi: 10.1158/ 0008-5472.can-10-1022

Hau, P., Fabel, K., Baumgart, U., Rummele, P., Grauer, O., Bock, A., et al. (2004). Pegylated liposomal doxorubicin-efficacy in patients with recurrent high-grade glioma. Cancer 100, 1199-1207. doi: 10.1002/cncr.20073

Hsu, F. T., Wei, Z. H., Hsuan, Y. C., Lin, W., Su, Y. C., Liao, C. H., et al. (2018). MRI tracking of polyethylene glycol-coated superparamagnetic iron oxide-labelled placenta-derived mesenchymal stem cells toward glioblastoma stem-like cells in a mouse model. Artif. Cells Nanomed. Biotechnol. 46, S448-S459.

Hua, L., Wang, Z., Zhao, L., Mao, H. L., Wang, G. H., Zhang, K. R., et al. (2018). Hypoxia-responsive lipid-poly-(hypoxic radiosensitized polyprodrug) nanoparticles for glioma chemo- and radiotherapy. Theranostics 8, 5088-5105. doi: $10.7150 /$ thno. 26225

Hua, M. Y., Liu, H. L., Yang, H. W., Chen, P. Y., Tsai, R. Y., Huang, C. Y., et al. (2011). The effectiveness of a magnetic nanoparticle-based delivery system for BCNU in the treatment of gliomas. Biomaterials 32, 516-527. doi: 10.1016/j. biomaterials.2010.09.065

Huang, L., Xu, C., Xu, P., Qin, Y., Chen, M., Feng, Q., et al. (2019). Intelligent photosensitive mesenchymal stem cells and cell-derived microvesicles for photothermal therapy of prostate cancer. Nanotheranostics 3, 41-53. doi: 10. $7150 /$ ntno. 28450

Huang, R. Y., Lin, Y. H., Lin, S. Y., Li, Y. N., Chiang, C. S., and Chang, C. W. (2019). Magnetic ternary nanohybrids for nonviral gene delivery of stem cells and applications on cancer therapy. Theranostics 9, 2411-2423. doi: 10.7150/ thno. 29326

Huang, X., Zhang, F., Wang, H., Niu, G., Choi, K. Y., Swierczewska, M., et al. (2013). Mesenchymal stem cell-based cell engineering with multifunctional mesoporous silica nanoparticles for tumor delivery. Biomaterials 34, 17721780. doi: 10.1016/j.biomaterials.2012.11.032

Huang, X., Zhang, F., Wang, Y., Sun, X., Choi, K. Y., Liu, D., et al. (2014). Design considerations of iron-based nanoclusters for noninvasive tracking of mesenchymal stem cell homing. ACS Nano 8, 4403-4414. doi: 10.1021/ nn 4062726

Hussein Kamareddine, M., Ghosn, Y., Tawk, A., Elia, C., Alam, W., Makdessi, J., et al. (2019). Organic nanoparticles as drug delivery systems and their potential role in the treatment of chronic myeloid leukemia. Technol. Cancer Res. Treat. $18,1533033819879902$.

Iser, I. C., Ceschini, S. M., Onzi, G. R., Bertoni, A. P., Lenz, G., and Wink, M. R. (2016). Conditioned medium from adipose-derived stem cells (ADSCs) promotes epithelial-to-mesenchymal-like transition (EMT-like) in glioma cells in vitro. Mol. Neurobiol. 53, 7184-7199. doi: 10.1007/s12035-0159585-4

Jabbarpour, Z., Kiani, J., Keshtkar, S., Saidijam, M., Ghahremani, M. H., and Ahmadbeigi, N. (2020). Effects of human placenta-derived mesenchymal stem cells with NK4 gene expression on glioblastoma multiforme cell lines. J. Cell. Biochem. 121, 1362-1373. doi: 10.1002/jcb.29371
Jagannathan, R., Irvin, G., Blanton, T., and Jagannathan, S. (2006). Organic nanoparticles: preparation, self-assembly, and properties. Adv. Funct. Mater. 16, 747-753. doi: 10.1002/adfm.200600003

Jager, E., and Giacomelli, F. C. (2015). Soft matter assemblies as nanomedicine platforms for cancer chemotherapy: a journey from market products towards novel approaches. Curr. Top. Med. Chem. 15, 328-344. doi: 10.2174/ 1568026615666150130152300

Jiang, X., Xin, H., Sha, X., Gu, J., Jiang, Y., Law, K., et al. (2011). PEGylated poly(trimethylene carbonate) nanoparticles loaded with paclitaxel for the treatment of advanced glioma: in vitro and in vivo evaluation. Int. J. Pharm. 420, 385-394. doi: 10.1016/j.ijpharm.2011.08.052

Jiao, H., Guan, F., Yang, B., Li, J., Song, L., Hu, X., et al. (2012). Human amniotic membrane derived-mesenchymal stem cells induce C6 glioma apoptosis in vivo through the Bcl-2/caspase pathways. Mol. Biol. Rep. 39, 467-473. doi: 10.1007/ s11033-011-0760-Z

Karlsson, J., Rui, Y., Kozielski, K. L., Placone, A. L., Choi, O., Tzeng, S. Y., et al. (2019). Engineered nanoparticles for systemic siRNA delivery to malignant brain tumours. Nanoscale 11, 20045-20057. doi: 10.1039/c9nr0 $4795 \mathrm{f}$

Kassis, I., Zangi, L., Rivkin, R., Levdansky, L., Samuel, S., Marx, G., et al. (2006). Isolation of mesenchymal stem cells from G-CSF-mobilized human peripheral blood using fibrin microbeads. Bone Marrow Transplant. 37, 967-976. doi: 10.1038/sj.bmt. 1705358

Katz, A. J., Tholpady, A., Tholpady, S. S., Shang, H., and Ogle, R. C. (2005). Cell surface and transcriptional characterization of human adipose-derived adherent stromal (hADAS) cells. Stem Cells 23, 412-423. doi: 10.1634/stemcells. 2004-0021

Kaur, P., Aliru, M. L., Chadha, A. S., Asea, A., and Krishnan, S. (2016). Hyperthermia using nanoparticles-Promises and pitfalls. Int. J. Hyperther. 32, 76-88. doi: 10.3109/02656736.2015.1120889

Kazmi, F., Vallis, K. A., Vellayappan, B. A., Bandla, A., Yukun, D., and Carlisle, R. (2020). Megavoltage radiosensitization of gold nanoparticles on a glioblastoma cancer cell line using a clinical platform. Int. J. Mol. Sci. 21:429. doi: 10.3390/ ijms 21020429

Kefayat, A., Ghahremani, F., Motaghi, H., and Amouheidari, A. (2019). Ultra-small but ultra-effective: folic acid-targeted gold nanoclusters for enhancement of intracranial glioma tumors' radiation therapy efficacy. Nanomed Nanotechnol. 16, 173-184. doi: 10.1016/j.nano.2018.12.007

Khawaja, A. M. (2011). The legacy of nanotechnology: revolution and prospects in neurosurgery. Int. J. Surg. 9, 608-614. doi: 10.1016/j.ijsu.2011.10.002

Kim, D. H., Rozhkova, E. A., Ulasov, I. V., Bader, S. D., Rajh, T., Lesniak, M. S., et al. (2010). Biofunctionalized magnetic-vortex microdiscs for targeted cancer-cell destruction. Nat. Mater. 9, 165-171. doi: 10.1038/nmat2591

Kim, R., Lee, S., Lee, J., Kim, M., Kim, W. J., Lee, H. W., et al. (2018). Exosomes derived from microRNA-584 transfected mesenchymal stem cells: novel alternative therapeutic vehicles for cancer therapy. BMB Rep. 51, 406-411. doi: 10.5483/bmbrep.2018.51.8.105

Kim, S. J., Lewis, B., Steiner, M. S., Bissa, U. V., Dose, C., and Frank, J. A. (2016). Superparamagnetic iron oxide nanoparticles for direct labeling of stem cells and in vivo MRI tracking. Contrast Med. Mol. Imaging 11, 55-64. doi: 10.1002/ cmmi. 1658

Kim, S. K., Cargioli, T. G., Machluf, M., Yang, W., Sun, Y., Al-Hashem, R., et al. (2005). PEX-producing human neural stem cells inhibit tumor growth in a mouse glioma model. Clin. Cancer Res. 11, 5965-5970. doi: 10.1158/1078-0432. ccr-05-0371

Kim, S. M., Jeong, C. H., Woo, J. S., Ryu, C. H., Lee, J. H., and Jeun, S. S. (2016). In vivo near-infrared imaging for the tracking of systemically delivered mesenchymal stem cells: tropism for brain tumors and biodistribution. Int. J. Nanomed. 11, 13-23. doi: 10.2147/ijn.s97073

Kim, T., Momin, E., Choi, J., Yuan, K., Zaidi, H., Kim, J., et al. (2011). Mesoporous silica-coated hollow manganese oxide nanoparticles as positive T1 contrast agents for labeling and MRI tracking of adipose-derived mesenchymal stem cells. J. Am. Chem. Soc. 133, 2955-2961. doi: 10.1021/ja1 084095

Kleinschmidt, K., Klinge, P. M., Stopa, E., Wallrapp, C., Glage, S., Geigle, P., et al. (2011). Alginate encapsulated human mesenchymal stem cells suppress syngeneic glioma growth in the immunocompetent rat. J. Microencapsul. 28, 621-627. doi: 10.3109/02652048.2011.599441 
Klimanskaya, I. (2019). "Embryonic stem cells: derivation, properties and challenges," in Principles of Regenerative Medicine. 3rd Edition ed, ed. A. Atala (Amsterdam: ElSevier).

Koo, Y. E., Reddy, G. R., Bhojani, M., Schneider, R., Philbert, M. A., Rehemtulla, A., et al. (2006). Brain cancer diagnosis and therapy with nanoplatforms. Adv. Drug Deliv. Rev. 58, 1556-1577. doi: 10.1016/j.addr.2006.09. 012

Kosaka, H., Ichikawa, T., Kurozumi, K., Kambara, H., Inoue, S., Maruo, T., et al. (2012). Therapeutic effect of suicide gene-transferred mesenchymal stem cells in a rat model of glioma. Cancer Gene Ther. 19, 572-578. doi: 10.1038/cgt.2012. 35

Kozielski, K. L., Ruiz-Valls, A., Tzeng, S. Y., Guerrero-Cazares, H., Rui, Y., Li, Y., et al. (2019). Cancer-selective nanoparticles for combinatorial siRNA delivery to primary human GBM in vitro and in vivo. Biomaterials 209, 79-87. doi: 10.1016/j.biomaterials.2019.04.020

Kunoh, T., Shimura, T., Kasai, T., Matsumoto, S., Mahmud, H., Khayrani, A. C., et al. (2019). Use of DNA-generated gold nanoparticles to radiosensitize and eradicate radioresistant glioma stem cells. Nanotechnology 30:055101. doi: 10. 1088/1361-6528/aaedd5

Kus, M., Alic, T. Y., Kirbiyik, C., Baslak, C., Kara, K., and Kara, D. A. (2018), "Chapter 24 - synthesis of nanoparticles," in Handbook of Nanomaterials for Industrial Applications, ed. C. Mustansar Hussain (Amsterdam: Elsevier), 392429.

Lammers, T., Peschke, P., Kuhnlein, R., Subr, V., Ulbrich, K., Debus, J., et al. (2007). Effect of radiotherapy and hyperthermia on the tumor accumulation of HPMA copolymer-based drug delivery systems. J. Control. Release 117, 333-341. doi: 10.1016/j.jconrel.2006.10.032

Lang, F. M., Hossain, A., Gumin, J., Momin, E. N., Shimizu, Y., Ledbetter, D., et al. (2018). Mesenchymal stem cells as natural biofactories for exosomes carrying miR-124a in the treatment of gliomas. Neuro Oncol. 20, 380-390. doi: $10.1093 /$ neuonc/nox152

Lara-Velazquez, M., Alkharboosh, R., Norton, E. S., Ramirez-Loera, C., Freeman, W. D., Guerrero-Cazares, H., et al. (2020). Chitosan-based non-viral gene and drug delivery systems for brain cancer. Front. Neurol. 11:740. doi: 10.3389/ fneur.2020.00740

Lathia, J. D., Li, M., Hall, P. E., Gallagher, J., Hale, J. S., Wu, Q., et al. (2012). Laminin alpha 2 enables glioblastoma stem cell growth. Ann. Neurol. 72, 766-778. doi: 10.1002/ana.23674

Lee, J., Elkahloun, A. G., Messina, S. A., Ferrari, N., Xi, D., Smith, C. L., et al. (2003). Cellular and genetic characterization of human adult bone marrowderived neural stem-like cells: a potential antiglioma cellular vector. Cancer Res. $63,8877-8889$.

Lee, H. K., Finniss, S., Cazacu, S., Bucris, E., Ziv-Av, A., Xiang, C., et al. (2013). Mesenchymal stem cells deliver synthetic microRNA mimics to glioma cells and glioma stem cells and inhibit their cell migration and self-renewal. Oncotarget 4, 346-361. doi: 10.18632/oncotarget.868

Lee, J. H., Warner, C. M., Jin, H. E., Barnes, E., Poda, A. R., Perkins, E. J., et al. (2017). Production of tunable nanomaterials using hierarchically assembled bacteriophages. Nat. Protoc. 12, 1999-2013. doi: 10.1038/nprot.20 17.085

Lee, Y. J., Galoforo, S. S., Berns, C. M., Erdos, G., Gupta, A. K., Ways, D. K., et al. (1995). Effect of ionizing radiation on AP-1 binding activity and basic fibroblast growth factor gene expression in drug-sensitive human breast carcinoma MCF7 and multidrug-resistant MCF-7/ADR cells. J. Biol. Chem. 270, 28790-28796. doi: $10.1074 / j b c .270 .48 .28790$

Li, Q., Wijesekera, O., Salas, S. J., Wang, J. Y., Zhu, M., Aprhys, C., et al. (2014). Mesenchymal stem cells from human fat engineered to secrete BMP4 are nononcogenic, suppress brain cancer, and prolong survival. Clin. Cancer Res. 20, 2375-2387. doi: 10.1158/1078-0432.ccr-13-1415

Li, S. P., Jiang, Q., Liu, S. L., Zhang, Y. L., Tian, Y. H., Song, C., et al. (2018). A DNA nanorobot functions as a cancer therapeutic in response to a molecular trigger in vivo. Nat. Biotechnol. 36, 258-264. doi: 10.1038/nbt. 4071

Li, X. T., Tang, W., Xie, H. J., Liu, S., Song, X. L., Xiao, Y., et al. (2019). The efficacy of RGD modified liposomes loaded with vinorelbine plus tetrandrine in treating resistant brain glioma. J. Liposome Res. 29, 21-34. doi: 10.1080/08982104.2017. 1408649
Li, Z., Bao, S., Wu, Q., Wang, H., Eyler, C., Sathornsumetee, S., et al. (2009). Hypoxia-inducible factors regulate tumorigenic capacity of glioma stem cells. Cancer Cell. 15, 501-513. doi: 10.1016/j.ccr.2009.03.018

Liang, K., Li, Z., Luo, Y., Zhang, Q., Yin, F., Xu, L., et al. (2020). Intelligent nanocomposites with intrinsic blood-brain-barrier crossing ability designed for highly specific MR imaging and sonodynamic therapy of glioblastoma. Small 16:e1906985.

Liao, L. Y., Liu, J., Dreaden, E. C., Morton, S. W., Shopsowitz, K. E., Hammond, P. T., et al. (2014). A convergent synthetic platform for single-nanoparticle combination cancer therapy: ratiometric loading and controlled release of cisplatin, doxorubicin, and camptothecin. J. Am. Chem. Soc. 136, 5896-5899. doi: $10.1021 / \mathrm{ja} 502011 \mathrm{~g}$

Liu, J., He, H., Xiao, D., Yin, S., Ji, W., Jiang, S., et al. (2018). Recent advances of plasmonic nanoparticles and their applications. Materials 11:1833. doi: 10. 3390/ma11101833

Liu, S., Yin, F., Zhao, M., Zhou, C., Ren, J., Huang, Q., et al. (2016). The homing and inhibiting effects of hNSCs-BMP4 on human glioma stem cells. Oncotarget 7, 17920-17931. doi: 10.18632/oncotarget.7472

Luque-Michel, E., Sebastian, V., Larrea, A., Marquina, C., and Blanco-Prieto, M. J. (2019). Co-encapsulation of superparamagnetic nanoparticles and doxorubicin in PLGA nanocarriers: development, characterization and in vitro antitumor efficacy in glioma cells. Eur. J. Pharm. Biopharm. 145, 65-75. doi: 10.1016/j. ejpb.2019.10.004

Ma, Y., Li, M., Liu, J., Pang, C., Zhang, J., Li, Y., et al. (2018). Location, isolation, and identification of mesenchymal stem cells from adult human sweat glands. Stem Cells Int. 2018, 2090276.

Madhankumar, A. B., Slagle-Webb, B., Wang, X., Yang, Q. X., Antonetti, D. A., Miller, P. A., et al. (2009). Efficacy of interleukin-13 receptor-targeted liposomal doxorubicin in the intracranial brain tumor model. Mol. Cancer Ther. 8, 648-654. doi: 10.1158/1535-7163.mct-08-0853

Mahato, D., De Biase, G., Ruiz-Garcia, H. J., Grover, S., Rosenfeld, S., QuiñonesHinojosa, A., et al. (2018). Impact of facility type and volume on post-surgical outcomes following diagnosis of WHO grade II glioma. J. Clin. Neurosci. 58, 34-41. doi: 10.1016/j.jocn.2018.10.078

Maier-Hauff, K., Rothe, R., Scholz, R., Gneveckow, U., Wust, P., Thiesen, B., et al. (2007). Intracranial thermotherapy using magnetic nanoparticles combined with external beam radiotherapy: results of a feasibility study on patients with glioblastoma multiforme. J. Neuro Oncol. 81, 53-60. doi: 10.1007/s11060-0069195-0

Mampre, D., Ehresman, J., Pinilla-Monsalve, G., Osorio, M. A. G., Olivi, A., Quinones-Hinojosa, A., et al. (2018). Extending the resection beyond the contrast-enhancement for glioblastoma: feasibility, efficacy, and outcomes. Br. J. Neurosurg. 32, 528-535. doi: 10.1080/02688697.2018.149 8450

Mangraviti, A., Tzeng, S. Y., Gullotti, D., Kozielski, K. L., Kim, J. E., Seng, M., et al. (2016). Non-virally engineered human adipose mesenchymal stem cells produce BMP4, target brain tumors, and extend survival. Biomaterials 100, 53-66. doi: 10.1016/j.biomaterials.2016.05.025

Mangraviti, A., Tzeng, S. Y., Kozielski, K. L., Wang, Y., Jin, Y., Gullotti, D., et al. (2015). Polymeric nanoparticles for nonviral gene therapy extend brain tumor survival in vivo. ACS Nano 9, 1236-1249. doi: 10.1021/nn504905q

Marenco-Hillembrand, L., Prevatt, C., Suarez-Meade, P., Ruiz-Garcia, H., Quinones-Hinojosa, A., and Chaichana, K. L. (2020). Minimally invasive surgical outcomes for deep-seated brain lesions treated with different tubular retraction systems: a systematic review and meta-analysis. World Neurosurg. [Epub ahead of print].

Martinez-Quintanilla, J., He, D., Wakimoto, H., Alemany, R., and Shah, K. (2015). Encapsulated stem cells loaded with hyaluronidase-expressing oncolytic virus for brain tumor therapy. Mol. Therapy 23, 108-118. doi: 10.1038/mt.2014. 204

Martinez-Rovira, I., Seksek, O., Dokic, I., Brons, S., Abdollahi, A., and Yousef, I. (2020). Study of the intracellular nanoparticle-based radiosensitization mechanisms in F98 glioma cells treated with charged particle therapy through synchrotron-based infrared microspectroscopy. Analyst 145, 2345-2356. doi: $10.1039 / \mathrm{c} 9 \mathrm{an} 02350 \mathrm{j}$

McGirt, M. J., Chaichana, K. L., Attenello, F. J., Weingart, J. D., Than, K., Burger, P. C., et al. (2008). Extent of surgical resection is independently associated 
with survival in patients with hemispheric infiltrating low-grade gliomas. Neurosurgery 63, 700-708. doi: 10.1227/01.neu.0000325729.41085.73

McGirt, M. J., Chaichana, K. L., Gathinji, M., Attenello, F. J., Than, K., Olivi, A., et al. (2009). Independent association of extent of resection with survival in patients with malignant brain astrocytoma. J. Neurosurg. 110, 156-162. doi: 10.3171/2008.4.17536

McNeeley, K. M., Karathanasis, E., Annapragada, A. V., and Bellamkonda, R. V. (2009). Masking and triggered unmasking of targeting ligands on nanocarriers to improve drug delivery to brain tumors. Biomaterials 30, 3986-3995. doi: 10.1016/j.biomaterials.2009.04.012

Meca-Cortes, O., Guerra-Rebollo, M., Garrido, C., Borros, S., Rubio, N., and Blanco, J. (2017). CRISPR/Cas9-mediated knockin application in cell therapy: a non-viral procedure for bystander treatment of glioma in mice. Mol. Ther. Nucleic Acids 8, 395-403. doi: 10.1016/j.omtn.2017.07.012

Meng, X., Ichim, T. E., Zhong, J., Rogers, A., Yin, Z., Jackson, J., et al. (2007). Endometrial regenerative cells: a novel stem cell population. J. Transl. Med. 5:57.

Meng, X., Zhao, Y., Han, B., Zha, C., Zhang, Y., Li, Z., et al. (2020). Dual functionalized brain-targeting nanoinhibitors restrain temozolomide-resistant glioma via attenuating EGFR and MET signaling pathways. Nat. Commun. 11:594.

Menon, L. G., Pratt, J., Yang, H. W., Black, P. M., Sorensen, G. A., and Carroll, R. S. (2012). Imaging of human mesenchymal stromal cells: homing to human brain tumors. J. Neuro Oncol. 107, 257-267. doi: 10.1007/s11060-011-0754-7

Miao, Z., Jin, J., Chen, L., Zhu, J., Huang, W., Zhao, J., et al. (2006). Isolation of mesenchymal stem cells from human placenta: comparison with human bone marrow mesenchymal stem cells. Cell Biol. Int. 30, 681-687. doi: 10.1016/j. cellbi.2006.03.009

Mooney, R., Roma, L., Zhao, D., Van Haute, D., Garcia, E., Kim, S. U., et al. (2014a). Neural stem cell-mediated intratumoral delivery of gold nanorods improves photothermal therapy. ACS Nano 8, 12450-12460. doi: 10.1021/nn505147w

Mooney, R., Weng, Y., Tirughana-Sambandan, R., Valenzuela, V., Aramburo, S., Garcia, E., et al. (2014b). Neural stem cells improve intracranial nanoparticle retention and tumor-selective distribution. Future Oncol. 10, 401-415. doi: $10.2217 /$ fon. 13.217

Morshed, R. A., Gutova, M., Juliano, J., Barish, M. E., Hawkins-Daarud, A., Oganesyan, D., et al. (2015). Analysis of glioblastoma tumor coverage by oncolytic virus-loaded neural stem cells using MRI-based tracking and histological reconstruction. Cancer Gene Ther. 22, 55-61. doi: 10.1038/cgt. 2014.72

Muroski, M. E., Morshed, R. A., Cheng, Y., Vemulkar, T., Mansell, R., Han, Y., et al. (2016). Controlled payload release by magnetic field triggered neural stem cell destruction for malignant glioma treatment. PLoS One 11:e0145129. doi: 10.1371/journal.pone. 0145129

Nakamura, K., Ito, Y., Kawano, Y., Kurozumi, K., Kobune, M., Tsuda, H., et al. (2004). Antitumor effect of genetically engineered mesenchymal stem cells in a rat glioma model. Gene Ther. 11, 1155-1164. doi: 10.1038/sj.gt.3302276

Neri, M., Maderna, C., Cavazzin, C., Deidda-Vigoriti, V., Politi, L. S., Scotti, G., et al. (2008). Efficient in vitro labeling of human neural precursor cells with superparamagnetic iron oxide particles: relevance for in vivo cell tracking. Stem Cells 26, 505-516. doi: 10.1634/stemcells.2007-0251

Ostrom, Q. T., Cioffi, G., Gittleman, H., Patil, N., Waite, K., Kruchko, C., et al. (2019). CBTRUS statistical report: primary brain and other central nervous system tumors diagnosed in the United States in 2012-2016. Neuro Oncol. 21(Suppl. 5), v1-v100.

Owens, D. E., and Peppas, N. A. (2006). Opsonization, biodistribution, and pharmacokinetics of polymeric nanoparticles. Int. J. Pharm. 307, 93-102. doi: 10.1016/j.ijpharm.2005.10.010

Park, J. H., Ryu, C. H., Kim, M. J., and Jeun, S. S. (2015). Combination therapy for gliomas using temozolomide and interferon-beta secreting human bone marrow derived mesenchymal stem cells. J. Korean Neurosurg. Soc. 57, 323-328. doi: $10.3340 / \mathrm{jkns.2015.57.5.323}$

Park, J. S., Qiao, L., Su, Z. Z., Hinman, D., Willoughby, K., McKinstry, $R$., et al. (2001). Ionizing radiation modulates vascular endothelial growth factor (VEGF) expression through multiple mitogen activated protein kinase dependent pathways. Oncogene 20, 3266-3280. doi: 10.1038/sj.onc.1204258

Parker Kerrigan, B. C., Hossain, A., Yamashita, S., and Lang, F. F. (2018). Stem cell therapy of gliomas. Prog. Neurol. Surg. 32, 124-151. doi: 10.1159/000469686
Patel, K. D., Singh, R. K., and Kim, H. W. (2019). Carbon-based nanomaterials as an emerging platform for theranostics. Mater. Horiz. 6, 434-469. doi: 10.1039/ c8mh00966j

Patki, S., Kadam, S., Chandra, V., and Bhonde, R. (2010). Human breast milk is a rich source of multipotent mesenchymal stem cells. Hum. Cell. 23, 35-40. doi: 10.1111/j.1749-0774.2010.00083.x

Pavon, L. F., Sibov, T. T., de Souza, A. V., da Cruz, E. F., Malheiros, S. M. F., Cabral, F. R., et al. (2018). Tropism of mesenchymal stem cell toward CD133(+) stem cell of glioblastoma in vitro and promote tumor proliferation in vivo. Stem Cell Res. Ther. 9:310.

Pendleton, C., Li, Q., Chesler, D. A., Yuan, K., Guerrero-Cazares, H., and Quinones-Hinojosa, A. (2013). Mesenchymal stem cells derived from adipose tissue vs bone marrow: in vitro comparison of their tropism towards gliomas. PLoS One 8:e58198. doi: 10.1371/journal.pone.0058198

Poloni, A., Rosini, V., Mondini, E., Maurizi, G., Mancini, S., Discepoli, G., et al. (2008). Characterization and expansion of mesenchymal progenitor cells from first-trimester chorionic villi of human placenta. Cytotherapy 10, 690-697. doi: $10.1080 / 14653240802419310$

Portney, N. G., and Ozkan, M. (2006). Nano-oncology: drug delivery, imaging, and sensing. Anal. Bioanal. Chem. 384, 620-630. doi: 10.1007/s00216-005-0247-7

Portnow, J., Synold, T. W., Badie, B., Tirughana, R., Lacey, S. F., D’Apuzzo, M., et al. (2017). Neural stem cell-based anticancer gene therapy: a first-in-human study in recurrent high-grade glioma patients. Clin. Cancer Res. 23, 2951-2960. doi: 10.1158/1078-0432.ccr-16-1518

Purbia, R., and Paria, S. (2015). Yolk/shell nanoparticles: classifications, synthesis, properties, and applications. Nanoscale 7, 19789-19873. doi: 10.1039/ c5nr04729c

Qi, N., Zhang, Y., Tang, X., and Li, A. (2020). Cationic/anionic polyelectrolyte (PLL/PGA) coated vesicular phospholipid gels (VPGs) loaded with cytarabine for sustained release and anti-glioma effects. Drug Des. Devel. Ther. 14, 18251836. doi: $10.2147 /$ dddt.s248362

Qiao, Y., Gumin, J., MacLellan, C. J., Gao, F., Bouchard, R., Lang, F. F., et al. (2018). Magnetic resonance and photoacoustic imaging of brain tumor mediated by mesenchymal stem cell labeled with multifunctional nanoparticle introduced via carotid artery injection. Nanotechnology 29:165101. doi: 10.1088/13616528/aaaf16

Ramos-Zúññiga, R., González-Pérez, O., Macías-Ornelas, A., Capilla-González, V., and Quiñones-Hinojosa, A. (2012). Ethical implications in the use of embryonic and adult neural stem cells. Stem Cells Int. 2012:470949.

Ranganathan, B., Miller, C., and Sinskey, A. (2018). Biocompatible synthetic and semi-synthetic polymers - a patent analysis. Pharm. Nanotechnol. 6, 28-37. doi: 10.2174/2211738505666171023152549

Rego, G. N. A., Mamani, J. B., Souza, T. K. F., Nucci, M. P., Silva, H. R. D., and Gamarra, L. F. (2019). Therapeutic evaluation of magnetic hyperthermia using Fe3O4-aminosilane-coated iron oxide nanoparticles in glioblastoma animal model. Einstein 17:eAO4786.

Rego, G. N. A., Nucci, M. P., Mamani, J. B., Oliveira, F. A., Marti, L. C., Filgueiras, I. S., et al. (2020). Therapeutic efficiency of multiple applications of magnetic hyperthermia technique in glioblastoma using aminosilane coated iron oxide nanoparticles: in vitro and in vivo study. Int. J. Mol. Sci. 21:958. doi: 10.3390/ ijms21030958

Reis, C. P., Neufeld, R. J., Ribeiro, A. J., and Veiga, F. (2006). Nanoencapsulation I. Methods for preparation of drug-loaded polymeric nanoparticles. Nanomedicine 2, 8-21. doi: 10.1016/j.nano.2005. 12.003

Ridge, S. M., Sullivan, F. J., and Glynn, S. A. (2017). Mesenchymal stem cells: key players in cancer progression. Mol. Cancer 16:31.

Roberts, R., Smyth, J. W., Will, J., Roberts, P., Grek, C. L., Ghatnekar, G. S., et al. (2020). Development of PLGA nanoparticles for sustained release of a connexin43 mimetic peptide to target glioblastoma cells. Mater. Sci. Eng. C Mater. Biol. Appl. 108:110191. doi: 10.1016/j.msec.2019.110191

Romero, G., and Moya, S. E. (2012). "Chapter 4 - synthesis of organic nanoparticles," in Frontiers of Nanoscience, Vol. 4, eds J. M. de la Fuente and V. Grazu (Amsterdam: Elsevier), 115-141. doi: 10.1016/b978-0-12-415769-9. 00004-2

Roubelakis, M. G., Pappa, K. I., Bitsika, V., Zagoura, D., Vlahou, A., Papadaki, H. A., et al. (2007). Molecular and proteomic characterization of human mesenchymal stem cells derived from amniotic fluid: comparison to bone 
marrow mesenchymal stem cells. Stem Cells Dev. 16, 931-952. doi: 10.1089/ scd.2007.0036

Ruan, S., Xie, R., Qin, L., Yu, M., Xiao, W., Hu, C., et al. (2019). Aggregable nanoparticles-enabled chemotherapy and autophagy inhibition combined with anti-PD-L1 antibody for improved glioma treatment. Nano Lett. 19, 8318-8332. doi: 10.1021/acs.nanolett.9b03968

Ruiz-Garcia, H., Alvarado-Estrada, K., Schiapparelli, P., Quinones-Hinojosa, A., and Trifiletti, D. M. (2020) Engineering three-dimensional tumor models to study glioma cancer stem cells and tumor microenvironment. Front. Cell. Neurosci. 14:558381. doi: 10.3389/fncel.2020.558381

Ryu, C. H., Park, S. H., Park, S. A., Kim, S. M., Lim, J. Y., Jeong, C. H., et al. (2011). Gene therapy of intracranial glioma using interleukin 12-secreting human umbilical cord blood-derived mesenchymal stem cells. Hum. Gene Ther. 22, 733-743. doi: 10.1089/hum.2010.187

Saxena, S., Pramod, B. J., Dayananda, B. C., and Nagaraju, K. (2015). Design, architecture and application of nanorobotics in oncology. Indian J. Cancer 52, 236-241. doi: 10.4103/0019-509x.175805

Shahar, T., Rozovski, U., Hess, K. R., Hossain, A., Gumin, J., Gao, F., et al. (2017). Percentage of mesenchymal stem cells in high-grade glioma tumor samples correlates with patient survival. Neuro Oncol. 19, 660-668.

Sharma, V. K., Filip, J., Zboril, R., and Varma, R. S. (2015). Natural inorganic nanoparticles-formation, fate, and toxicity in the environment. Chem. Soc. Rev. 44, 8410-8423. doi: 10.1039/c5cs00236b

Shen, Y., Wu, C., Uyeda, T. Q. P., Plaza, G. R., Liu, B., Han, Y., et al. (2017). Elongated nanoparticle aggregates in cancer cells for mechanical destruction with low frequency rotating magnetic field. Theranostics 7, 1735-1748. doi: $10.7150 /$ thno. 18352

Shi, D., Mi, G., Shen, Y., and Webster, T. J. (2019). Glioma-targeted dual functionalized thermosensitive Ferri-liposomes for drug delivery through an in vitro blood-brain barrier. Nanoscale 11, 15057-15071. doi: 10.1039/ c9nr03931g

Singh, S. K., Clarke, I. D., Terasaki, M., Bonn, V. E., Hawkins, C., Squire, J., et al. (2003). Identification of a cancer stem cell in human brain tumors. Cancer Res. 63, 5821-5828.

Smith, C. L., Chaichana, K. L., Lee, Y. M., Lin, B., Stanko, K. M., O'Donnell, T., et al. (2015). Pre-exposure of human adipose mesenchymal stem cells to soluble factors enhances their homing to brain cancer. Stem Cells Transl. Med. 4, 239-251. doi: 10.5966/sctm.20 14-0149

Snyder, E. Y., Deitcher, D. L., Walsh, C., Arnold-Aldea, S., Hartwieg, E. A., and Cepko, C. L. (1992). Multipotent neural cell lines can engraft and participate in development of mouse cerebellum. Cell 68, 33-51. doi: 10.1016/0092-8674(92) 90204-p

Sonabend, A. M., Ulasov, I. V., Tyler, M. A., Rivera, A. A., Mathis, J. M., and Lesniak, M. S. (2008). Mesenchymal stem cells effectively deliver an oncolytic adenovirus to intracranial glioma. Stem Cells 26, 831-841. doi: 10.1634/ stemcells.2007-0758

Soppimath, K. S., Tan, D. C.-W., and Yang, Y.-Y. (2005). pH-triggered thermally responsive polymer core-shell nanoparticles for drug delivery. Adv. Mater. 17, 318-323. doi: 10.1002/adma.200401057

Sousa, F., Dhaliwal, H. K., Gattacceca, F., Sarmento, B., and Amiji, M. M. (2019) Enhanced anti-angiogenic effects of bevacizumab in glioblastoma treatment upon intranasal administration in polymeric nanoparticles. J. Control. Release 309, 37-47. doi: 10.1016/j.jconrel.2019.07.033

Spina, G., Quarenghi, F., Rodenghi, F., Matscher, R., and Lavagnini, A. (1975). [Gastrokinetic effect of Vincamine]. Farmaco Prat. 30, 512-522.

Stupp, R., Mason, W. P., van den Bent, M. J., Weller, M., Fisher, B., Taphoorn, M. J., et al. (2005). Radiotherapy plus concomitant and adjuvant temozolomide for glioblastoma. N. Engl. J. Med. 352, 987-996.

Suarez-Meade, P., Marenco-Hillembrand, L., Prevatt, C., MurguiaFuentes, R., Mohamed, A., Alsaeed, T., et al. (2020). Awake vs. asleep motor mapping for glioma resection: a systematic review and metaanalysis. Acta Neurochir. 162, 1709-1720. doi: 10.1007/s00701-02004357-y

Svensson, A., Ramos-Moreno, T., Eberstal, S., Scheding, S., and Bengzon, J. (2017). Identification of two distinct mesenchymal stromal cell populations in human malignant glioma. J. Neuro Oncol. 131, 245-254. doi: 10.1007/s11060-016$2302-y$
Takahashi, K., and Yamanaka, S. (2006). Induction of pluripotent stem cells from mouse embryonic and adult fibroblast cultures by defined factors. Cell 126, 663-676. doi: 10.1016/j.cell.2006.07.024

Tamura, R., Miyoshi, H., Morimoto, Y., Oishi, Y., Sampetrean, O., Iwasawa, C., et al. (2020). Gene therapy using neural stem/progenitor cells derived from human induced pluripotent stem cells: visualization of migration and bystander killing effect. Hum. Gene Ther. 31, 352-366. doi: 10.1089/hum.2019.326

Tanrikulu, B., Ziyal, I., and Bayri, Y. (2019). In vitro effects of mesenchymal stem cells and various agents on apoptosis of glioblastoma cells. Turkish neurosurgery 29, 26-32.

Thimsen, E., Johnson, M., Zhang, X., Wagner, A. J., Mkhoyan, K. A., Kortshagen, U. R., et al. (2014). High electron mobility in thin films formed via supersonic impact deposition of nanocrystals synthesized in nonthermal plasmas. Nat. Commun. 5:5822.

Thu, M. S., Najbauer, J., Kendall, S. E., Harutyunyan, I., Sangalang, N., Gutova, M., et al. (2009). Iron labeling and pre-clinical MRI visualization of therapeutic human neural stem cells in a murine glioma model. PLoS One 4:e7218. doi: 10.1371/journal.pone.0007218

Tian, M., Ticer, T., Wang, Q., Walker, S., Pham, A., Suh, A., et al. (2020). Adipose-derived biogenic nanoparticles for suppression of inflammation. Small 16:e1904064.

Tirughana, R., Metz, M. Z., Li, Z., Hall, C., Hsu, D., Beltzer, J., et al. (2018). GMP production and scale-up of adherent neural stem cells with a quantum cell expansion system. Mol. Ther. Methods Clin. Dev. 10, 48-56. doi: 10.1016/j. omtm.2018.05.006

Tzeng, S. Y., Wilson, D. R., Hansen, S. K., Quiñones-Hinojosa, A., and Green, J. J. (2016). Polymeric nanoparticle-based delivery of TRAIL DNA for cancerspecific killing. Bioeng. Transl. Med. 1, 149-159. doi: 10.1002/btm2.10019

Uhl, M., Weiler, M., Wick, W., Jacobs, A. H., Weller, M., and Herrlinger, U. (2005). Migratory neural stem cells for improved thymidine kinase-based gene therapy of malignant gliomas. Biochem. Biophys. Res. Commun. 328, 125-129. doi: 10.1016/j.bbrc.2004.12.164

Ullah, I., Chung, K., Bae, S., Li, Y., Kim, C., Choi, B., et al. (2020). Nose-tobrain delivery of cancer-targeting paclitaxel-loaded nanoparticles potentiates anti-tumor effects in malignant glioblastoma. Mol. Pharm. 17, 1193-1204. doi: 10.1021/acs.molpharmaceut.1029b01215

van Eekelen, M., Sasportas, L. S., Kasmieh, R., Yip, S., Figueiredo, J. L., Louis, D. N., et al. (2010). Human stem cells expressing novel TSP-1 variant have antiangiogenic effect on brain tumors. Oncogene 29, 3185-3195. doi: 10.1038/onc. 2010.75

van Landeghem, F. K., Maier-Hauff, K., Jordan, A., Hoffmann, K. T., Gneveckow, U., Scholz, R., et al. (2009). Post-mortem studies in glioblastoma patients treated with thermotherapy using magnetic nanoparticles. Biomaterials 30, 52-57. doi: 10.1016/j.biomaterials.2008.09.044

Wagner, W., Wein, F., Seckinger, A., Frankhauser, M., Wirkner, U., Krause, U., et al. (2005). Comparative characteristics of mesenchymal stem cells from human bone marrow, adipose tissue, and umbilical cord blood. Exp. Hematol. 33, 1402-1416. doi: 10.1016/j.exphem.2005.07.003

Wang, C. H., Chiou, S. H., Chou, C. P., Chen, Y. C., Huang, Y. J., and Peng, C. A. (2011). Photothermolysis of glioblastoma stem-like cells targeted by carbon nanotubes conjugated with CD133 monoclonal antibody. Nanomedicine 7, 69-79. doi: 10.1016/j.nano.2010.06.010

Wang, H., Li, L., Ye, J., Wang, R., Wang, R., Hu, J., et al. (2020). Improving the oral bioavailability of an anti-glioma prodrug CAT3 using novel solid lipid nanoparticles containing oleic acid-CAT3 conjugates. Pharmaceutics 12:E126.

Wang, N., Sun, P., Lv, M., Tong, G., Jin, X., and Zhu, X. (2017). Mustard-inspired delivery shuttle for enhanced blood-brain barrier penetration and effective drug delivery in glioma therapy. Biomater. Sci. 5, 1041-1050. doi: 10.1039/ c7bm00133a

Wang, X., Gao, J., Ouyang, X., Wang, J., Sun, X., and Lv, Y. (2018). Mesenchymal stem cells loaded with paclitaxel-poly(lactic-co-glycolic acid) nanoparticles for glioma-targeting therapy. Int. J. Nanomed. 13, 5231-5248. doi: 10.2147/ijn. s167142

Wang, X., Tian, Y., Liao, X., Tang, Y., Ni, Q., Sun, J., et al. (2020). Enhancing selective photosensitizer accumulation and oxygen supply for high-efficacy photodynamic therapy toward glioma by 5-aminolevulinic acid loaded nanoplatform. J. Coll. Interf. Sci. 565, 483-493. doi: 10.1016/j.jcis.2020. 01.020 
Wegscheid, M. L., Morshed, R. A., Cheng, Y., and Lesniak, M. S. (2014). The art of attraction: applications of multifunctional magnetic nanomaterials for malignant glioma. Expert Opin. Drug Deliv. 11, 957-975. doi: 10.1517/ 17425247.2014.912629

Wei, C., and Zhao, Y. S. (2016). Photonic applications of metal-dielectric heterostructured nanomaterials. ACS Appl. Mater. Inter. 8, 3703-3713. doi: 10.1021/acsami.5b08086

Wilson, D. R., Mosenia, A., Suprenant, M. P., Upadhya, R., Routkevitch, D., Meyer, R. A., et al. (2017a). Continuous microfluidic assembly of biodegradable poly(beta-amino ester)/DNA nanoparticles for enhanced gene delivery. J. Biomed. Mater. Res. A 105, 1813-1825. doi: 10.1002/jbm.a.36033

Wilson, D. R., Routkevitch, D., Rui, Y., Mosenia, A., Wahlin, K. J., QuinonesHinojosa, A., et al. (2017b). A triple-fluorophore-labeled nucleic acid pH nanosensor to investigate non-viral gene delivery. Mol. Ther. 25, 1697-1709. doi: 10.1016/j.ymthe.2017.04.008

Wu, X., Hu, J., Zhou, L., Mao, Y., Yang, B., Gao, L., et al. (2008). In vivo tracking of superparamagnetic iron oxide nanoparticle-labeled mesenchymal stem cell tropism to malignant gliomas using magnetic resonance imaging. Laboratory investigation. J. Neurosurg. 108, 320-329. doi: 10.3171/jns/2008/108/2/0320

Xu, B., Zhang, Q., Luo, X., Ning, X., Luo, J., Guo, J., et al. (2020). Selenium nanoparticles reduce glucose metabolism and promote apoptosis of glioma cells through reactive oxygen species-dependent manner. Neuroreport 31, 226-234. doi: 10.1097/wnr.0000000000001386

Xu, Z. P., Zeng, Q. H., Lu, G. Q., and Yu, A. B. (2006). Inorganic nanoparticles as carriers for efficient cellular delivery. Chem. Eng. Sci. 61, 1027-1040. doi: 10.1016/j.ces.2005.06.019

Yamazoe, T., Koizumi, S., Yamasaki, T., Amano, S., Tokuyama, T., and Namba, H. (2015). Potent tumor tropism of induced pluripotent stem cells and induced pluripotent stem cell-derived neural stem cells in the mouse intracerebral glioma model. Int. J. Oncol. 46, 147-152. doi: 10.3892/ijo.2014.2702

Ye, C., Pan, B., Xu, H., Zhao, Z., Shen, J., Lu, J., et al. (2019). Co-delivery of GOLPH3 siRNA and gefitinib by cationic lipid-PLGA nanoparticles improves EGFR-targeted therapy for glioma. J. Mol. Med. 97, 1575-1588. doi: 10.1007/ s00109-019-01843-4

Yi, D., Xiang, W., Zhang, Q., Cen, Y., Su, Q., Zhang, F., et al. (2018). Human glioblastoma-derived mesenchymal stem cell to pericytes transition and angiogenic capacity in glioblastoma microenvironment. Cell. Physiol. Biochem. 46, 279-290. doi: 10.1159/000488429

Yong, R. L., Shinojima, N., Fueyo, J., Gumin, J., Vecil, G. G., Marini, F. C., et al. (2009). Human bone marrow-derived mesenchymal stem cells for intravascular delivery of oncolytic adenovirus Delta24-RGD to human gliomas. Cancer Res. 69, 8932-8940. doi: 10.1158/0008-5472.can08-3873

Young, J. S., Morshed, R. A., Kim, J. W., Balyasnikova, I. V., Ahmed, A. U., and Lesniak, M. S. (2014). Advances in stem cells, induced pluripotent stem cells, and engineered cells: delivery vehicles for anti-glioma therapy. Expert Opin. Drug Deliv. 11, 1733-1746. doi: 10.1517/17425247.2014.93 7420

Yu, D., Khan, O. F., Suva, M. L., Dong, B., Panek, W. K., Xiao, T., et al. (2017). Multiplexed RNAi therapy against brain tumor-initiating cells via lipopolymeric nanoparticle infusion delays glioblastoma progression. Proc. Natl. Acad. Sci. U.S.A. 114, E6147-E6156.
Yu, M. A., Su, D. Y., Yang, Y. Y., Qin, L., Hu, C., Liu, R., et al. (2019). D-T7 peptide-modified PEGylated bilirubin nanoparticles loaded with cediranib and paclitaxel for antiangiogenesis and chemotherapy of glioma. ACS Appl. Mater. Inter. 11, 176-186. doi: 10.1021/acsami.8b 16219

Yuan, J. Z., Levitin, H. M., Frattini, V., Bush, E. C., Boyett, D. M., Samanamud, J., et al. (2018). Single-cell transcriptome analysis of lineage diversity in high-grade glioma. Genome Med. 10:57.

Zeddou, M., Briquet, A., Relic, B., Josse, C., Malaise, M. G., Gothot, A., et al. (2010). The umbilical cord matrix is a better source of mesenchymal stem cells (MSC) than the umbilical cord blood. Cell Biol. Int. 34, 693-701. doi: 10.1042/cbi20090414

Zhang, P., Miska, J., Lee-Chang, C., Rashidi, A., Panek, W. K., An, S., et al. (2019). Therapeutic targeting of tumor-associated myeloid cells synergizes with radiation therapy for glioblastoma. Proc. Natl. Acad. Sci. U.S.A. 116, 23714-23723. doi: 10.1073/pnas.1906346116

Zhang, Q., Xiang, W., Yi, D. Y., Xue, B. Z., Wen, W. W., Abdelmaksoud, A., et al. (2018). Current status and potential challenges of mesenchymal stem cell-based therapy for malignant gliomas. Stem Cell Res. Ther. 9:228.

Zhao, J., Liu, P., Ma, J., Li, D., Yang, H., Chen, W., et al. (2019). Enhancement of radiosensitization by silver nanoparticles functionalized with polyethylene glycol and aptamer As1411 for glioma irradiation therapy. Int. J. Nanomed. 14, 9483-9496. doi: 10.2147/ijn.s224160

Zhao, M., Zhao, M., Fu, C., Yu, Y., and Fu, A. (2018). Targeted therapy of intracranial glioma model mice with curcumin nanoliposomes. Int. J. Nanomed. 13, 1601-1610. doi: 10.2147/ijn.s157019

Zhu, H., Cao, X., Cai, X., Tian, Y., Wang, D., Qi, J., et al. (2020). Pifithrin-mu incorporated in gold nanoparticle amplifies pro-apoptotic unfolded protein response cascades to potentiate synergistic glioblastoma therapy. Biomaterials 232:119677. doi: 10.1016/j.biomaterials.2019.119677

Zhu, J., Zhou, L., and XingWu, F. (2006). Tracking neural stem cells in patients with brain trauma. N. Engl. J. Med. 355, 2376-2378. doi: 10.1056/nejmc055304

ZhuGe, D. L., Wang, L. F., Chen, R., Li, X. Z., Huang, Z. W., Yao, Q., et al. (2019). Cross-linked nanoparticles of silk fibroin with proanthocyanidins as a promising vehicle of indocyanine green for photo-thermal therapy of glioma. Artif. Cells Nanomed. Biotechnol. 47, 4293-4304. doi: 10.1080/21691401.2019. 1699819

Zuk, P. A., Zhu, M., Mizuno, H., Huang, J., Futrell, J. W., Katz, A. J., et al. (2001). Multilineage cells from human adipose tissue: implications for cell-based therapies. Tissue Eng. 7, 211-228. doi: 10.1089/107632701300062859

Conflict of Interest: The authors declare that the research was conducted in the absence of any commercial or financial relationships that could be construed as a potential conflict of interest.

Copyright (C) 2020 Ruiz-Garcia, Alvarado-Estrada, Krishnan, Quinones-Hinojosa and Trifiletti. This is an open-access article distributed under the terms of the Creative Commons Attribution License (CC BY). The use, distribution or reproduction in other forums is permitted, provided the original author(s) and the copyright owner(s) are credited and that the original publication in this journal is cited, in accordance with accepted academic practice. No use, distribution or reproduction is permitted which does not comply with these terms. 